Article

\title{
Research on Government Subsidy Strategies for the Development of Agricultural Products E-Commerce
}

\author{
Yaoguang Zhong ${ }^{1}\left(\mathbb{D}\right.$, Ivan Ka Wai Lai ${ }^{2}\left(\mathbb{D}\right.$, Fangfang Guo ${ }^{3}$ and Huajun Tang ${ }^{4, *(\mathbb{D}}$ \\ 1 School of Business, Dongguan Polytechnic, Dongguan 523808, China; zhongyg@dgpt.edu.cn \\ 2 Faculty of International Tourism and Management, City University of Macau, Macau 999078, China; \\ ivanlai@cityu.mo \\ 3 School of Economics and Management, Dongguan University of Technology, Dongguan 523808, China; \\ guoff@dgut.edu.cn \\ 4 School of Business, Macau University of Science and Technology, Macau 999078, China \\ * Correspondence: hjtang@must.edu.mo; Tel.: +853-8897-2874
}

Citation: Zhong, Y.; Lai, I.K.W.; Guo, F.; Tang, H. Research on Government Subsidy Strategies for the Development of Agricultural Products E-Commerce. Agriculture 2021, 11, 1152. https://doi.org/ 10.3390/agriculture11111152

Academic Editor:

Giuseppe Timpanaro

Received: 12 October 2021

Accepted: 7 November 2021

Published: 17 November 2021

Publisher's Note: MDPI stays neutral with regard to jurisdictional claims in published maps and institutional affiliations.

Copyright: (C) 2021 by the authors. Licensee MDPI, Basel, Switzerland. This article is an open access article distributed under the terms and conditions of the Creative Commons Attribution (CC BY) license (https:/ / creativecommons.org/licenses/by/ $4.0 /)$.

\begin{abstract}
In many countries, the governments support the development of local agriculture through subsidization. Subsidizing the sales of agricultural products through E-commerce channels is a way to support the development of agriculture in China. This study aims to develop a profit model and apply Stackelberg game theory to determine which type of subsidies and decision-making can provide the maximum benefits for agricultural products E-commerce supply chains. The results indicate that for both centralized decisions and decentralized decisions, the subsidizing to the agricultural cooperative is better than the subsidizing to consumers and no subsidization. The sales volume, preservation level, sales efforts, and overall profit of the agricultural products E-commerce supply chain are significantly higher. It suggests that the government should play a leading role to support the development of agricultural products E-commerce. This study contributes to agricultural research by developing a profit model to examine the effects of different government subsidy strategies on each member of the agricultural online shopping supply chain. Recommendations are provided for agricultural cooperatives, E-commerce platforms, and the government to improve the quality and sales of agricultural products through online shopping channels.
\end{abstract}

Keywords: Stackelberg game; government subsidies; agricultural products supply chain; sales efforts

\section{Introduction}

The revenue of E-commerce in China has increased from 34.81 trillion yuan in 2019 to 37.21 trillion yuan in 2020. In the era of online shopping, people have become accustomed to purchasing different types of products online, for example, clothing, luggage, digital, mother and baby, snacks, books, etc. Among the many products, agricultural products are also indispensable daily consumption products [1]. Although there are growth opportunities for the E-commerce of agricultural products (E-commerce of agricultural products market report, 2020), its development is different from other daily products. Huo and $\mathrm{Mu}$ [2] pointed out three problems for agricultural products E-commerce. They are outlined as such: (1) the slow development of electronic commerce in traditional agricultural cooperatives, (2) the quality of agricultural products selling online, and (3) the government does not know how to support the development of E-commerce of agricultural products. Therefore, to have a sustainable development of agricultural products E-commerce, research is needed to solve these three problems.

Compared with other commercial products, E-commerce studies in agricultural products are rare [3]. E-commerce of agricultural products refers to online shopping platforms for sales of agricultural products and transactions with customers [3]. For this E-commerce supply chain, there are three major stakeholders: agricultural cooperatives, online shopping platforms, and customers. Major online shopping platforms for agricultural products 
E-commerce in China are Alibaba, JD, Pinduoduo, Tootoo, Meituan, etc. [4]. As for other daily products, their sales effort for agricultural products directly influences the online sales volume $[5,6]$ and indirectly affects the sustainable development of the agricultural products E-commerce. The agricultural products selling online include nuts and snacks, tea, seafood, fresh fruits, and vegetables. Due to the storage issue, the major agricultural products in the past are dried goods such as nuts. In recent years, the development of cold-chain logistics technology has provided an important guarantee for the online sales of fresh agricultural products. The housing economy spawned after the outbreak of COVID-19 has prompted more and more consumers to buy fresh fruits and vegetables on the Internet shopping platform. Therefore, keeping the freshness of agricultural products is the critical quality issue for sustainably developing agricultural products E-commerce [7].

From the above discussion, for sustainable development of agricultural products E-commerce, online shopping platforms take the role of sales promotion. Agricultural cooperatives undertake the role of maintaining the quality of agricultural products. Then, what is the role of the government? As for other business development such as policy support for online sales of agricultural products [8], the government could provide subsidizations for the sustainable development of agricultural products E-commerce. However, different countries have provided different forms of support to develop the agricultural products E-commerce. For example, the Thai government directly supported farmers to shift from traditional agricultural systems to e-agriculture systems [9]. The German government has invested in the construction of agricultural E-commerce websites for some farms and farmers, and the Japanese government subsidized farmers to buy computers to improve farmers' knowledge of the network [10], while Bangladesh heavily subsidized E-commerce platforms for agricultural products [11]. The Chinese government supports the purchase of agricultural products by issuing consumption vouchers. However, for the subsidizations, there are three options, subsidize to (1) agricultural cooperatives, (2) online shopping platforms, and (3) customers. For the subsidization arrangements, there are two options, (1) centralized decision-making and (2) decentralized decision-making. Considering the above options, the research question of this study is 'What is the subsidization strategy that provides the maximum benefits for agricultural products E-commerce supply chains?' Providing an answer to this answer will help the sustainable development of agricultural products E-commerce.

This study aims to develop a profit model and apply Stackelberg game theory to determine which type of subsidies and decision-making can provide the maximum benefits for agricultural products E-commerce supply chains. This study contributes to agriculture research by promoting the development of agricultural products E-commerce, identifying the role of each party in the agricultural products E-commerce supply chain, and solving the three issues for agricultural products E-commerce mentioned by Huo and $\mathrm{Mu}$ [2]. It also contributes to the E-commerce supply chain research by offering a profit model that includes the issues of agricultural products E-commerce under different government subsidization strategies. Researchers in E-commerce supply chain can apply this model for their further studies in other types of online products. Finally, this study provides recommendations for agricultural cooperatives, online shopping platforms, and the government for implementing the subsidization strategies.

\section{Literature Review}

\subsection{E-Commerce Agricultural Supply Chains}

A traditional agricultural product supply chain includes multiple sales links such as agricultural product brokers, wholesalers, and retail terminals, which have disadvantages such as a high rate of loss of agricultural products, asymmetric information, and high logistics costs [12,13]. E-commerce of agricultural products can realize 'point-to-point' sales, and the E-commerce of agricultural products has advantages such as effectively reducing intermediate sales links, improving logistics and distribution efficiency, reducing agricultural product loss, and increasing agricultural product sales [14,15]. According to 
Ali's E-commerce white paper on agricultural products, in 2020, the online retail sales of China's agricultural products reached 379.5 billion yuan, a year-on-year increase of $27 \%$. Because of its disintermediation, the E-commerce agricultural supply chain can effectively meet the new market demand by changing its supply chain structure in supplying agricultural products. A typical E-commerce agricultural supply chain consists of three parties, agricultural cooperatives, online shopping platforms, and customers [16].

With the development of express delivery of E-commerce, consumers' awareness of online consumption was improved; this creates an opportunity for developing the Ecommerce of agricultural products. Many scholars have tried to find ways to support the development of the E-commerce of agricultural products. For example, Chiang et al. [17] first verified through theoretical models that introducing direct channels on the basis of traditional agricultural channels will help agricultural supply chains improve their overall profitability. Hsiao and Chen [18] found that when agricultural cooperatives sell agricultural products to consumers through E-commerce, on the one hand, it can attract online shoppers to buy; on the other hand, it can effectively reduce the double marginalization. Yan et al. [19] studied the optimal decision-making in addressing the agricultural supply chain's concern on the freshness of agricultural products. Zhang et al. [20] compared the online and offline pre-sale strategy of fresh agricultural products based on service efforts. Mueller [21] analysed the impact of E-commerce on the agricultural product market from the perspective of supply chain and value chain. He argued that the existing E-commerce of agricultural products has problems such as low logistics efficiency, high cost, and low service level, which cannot satisfy the consumers for high quality and efficiency. Therefore, improving the freshness of agricultural products and sales efforts are particularly important for the sustainable development of agricultural products E-commerce [7].

\subsection{Government Subsidy Policy}

Government subsidy plays a role in developing the economy, promoting enterprise technology or product innovation and reducing poverty. Research on government subsidy mainly focuses on low-carbon energy conservation and emission reduction [22,23], recycling of waste products [24,25], and old for new [26,27]. For example, the study of Wang et al. [28] showed that government subsidy has improved the overall operating efficiency of the closed-loop supply chain of low-carbon E-commerce and the total social surplus. Xue et al. [29] and Huang et al. [23] constructed a green supply chain decisionmaking model for energy-saving products under different government subsidy schemes. Their results supported the fact that the government subsidy can significantly improve social welfare and promote the improvement of energy-saving products. Ma et al. [30] tested the effect of government subsidy on retailers and manufacturers and confirmed that government subsidy can improve the level of green innovation. For green product marketing, Meng et al. [31] found that government subsidy helps to promote the sales of green products, thereby expanding the market share of green products.

Other than the subsidization of environmental products, governments around the world have formulated different policies to subsidize agricultural products to promote the sustainable development of agriculture [32]. The subsidy policies for agriculture have become a common and important incentive strategy for sustainable agricultural development [33]. For example, European governments provided agricultural subsidies that exceed $40 \%$ of their annual budgets [34]. The Indian government provided farmers with price subsidies, infrastructure subsidies, and export subsidies to support agricultural development. During the EU programming period 2007-2013, Aragon received agricultural subsidies worth 4055 million Euros [35]. For supporting the government's subsidy policy in agriculture development, researchers have built different models to examine the outcomes of government subsidy policy. Akkaya et al. [36] found that the agricultural subsidy policy can improve farmers' planting scale, increase farmers' income and achieve higher cost returns. Yadav et al. [37] found that the government subsidy in rural areas can help alleviate the poverty of the economically backward population. Kang et al. [38] constructed a series 
of game models of a government-subsidized green supply chain to show how to overcome the issue of insufficient farmers' funds.

Recently, governments around the world started to subsidize the development of agricultural products E-commerce. For example, in 2018, Bangladesh used part of Taka 44.81 billion to subsidize E-commerce platforms for purchasing agricultural products in the countryside. In 2020, Russia used around 81.2 billion rubles to subsidize small and medium-sized enterprises, including E-commerce platforms that go to the countryside to purchase agricultural products. Recently, the Chinese government has also introduced a series of agricultural subsidy policies, including some agricultural subsidy policies for E-commerce. However, among different agricultural subsidy policies for E-commerce, which one can provide the most benefits for the agricultural products E-commerce supply chains is still a question.

\section{Model Description and Assumptions}

\subsection{Model Description}

This study applies the Stackelberg game model that was widely used to study government subsidy research such as electric vehicle sharing [39]. This study consists of four parties: the government, a farmer cooperative, an E-commerce platform, and customers. In the Stackelberg game [40], one party acts as a leader, and the rest are its followers. The leader chooses its best-response strategy, then, the followers react rationally to the leader's action. This research takes agricultural products as an example to study the decision-making model of two main bodies composed of a farmer cooperative $f$ and an E-commerce platform $l$. Assuming that the farmer cooperative only sells one kind of agricultural product, the E-commerce platform $l$ purchases that kind of agricultural product from the farmer cooperative $f$ and sells them online to consumers. Cooperatives can give farmers a better position in price negotiations, and even lead [41]. Referring to the literature [7], consumer behaviour is affected by (a) the selling price, (b) the freshness of agricultural products, and (c) the sales efforts of the E-commerce platform. In this study, referring to the literature [20], the E-commerce platform is the leader [42,43]. It determines the selling price and sales efforts of the agricultural product according to market demand. The farmer cooperative is the follower. It determines the freshness level and wholesale price of the agricultural product. The E-commerce platform adjusts the selling prices in order to maximize the benefits of the e-supply chain.

\subsection{Model Symbol Description}

The descriptions of symbols involved in the model of this research are shown in Table 1.

\subsection{Research Assumptions}

The establishment of the model in this study is based on the following assumptions.

(1) All members in the supply chain system are risk-neutral.

(2) All the members are rational who make their own decisions to maximize their own profit.

(3) The E-commerce platform only sells one kind of agricultural product. The product demand is affected by the price, freshness of the agricultural product and the sales efforts of the E-commerce platform.

(4) Using the function form used by Ghosh and Shah [44] and Zhao and Wei [45], the cost function of the farmer cooperative to improve the freshness of agricultural products is $g(s)=\frac{1}{2} k s^{2}(k>0)$. It represents the cost that the farmer cooperative pays to improve the freshness of agricultural products; while $k$ indicates the sensitivity coefficient of the farmer cooperative to improve the freshness of agricultural products.

(5) Drawing on the functional form used by Ma et al. [46], the functional relationship between the sales promotion cost and sales efforts of the E-commerce platform is 
$c(e)=\frac{1}{2} \gamma e^{2}$. It represents the cost that the E-commerce platform pays to increase sales through promotional efforts; while $\gamma$ indicates the sensitivity coefficient of the E-commerce platform to promote efforts.

(6) $\Delta p$ represents the marginal profit of an E-commerce platform. To ensure the profitability of the E-commerce platform, $\Delta p>0$.

Table 1. Research model symbols and descriptions.

\begin{tabular}{|c|c|c|c|}
\hline Symbol & Meaning & Symbol & Meaning \\
\hline$D$ & Market demand for product & $e$ & $\begin{array}{l}\text { Sales efforts of the E-commerce } \\
\text { platform }\end{array}$ \\
\hline$D_{0}$ & Market base demand for product & C & $\begin{array}{c}\text { Planting cost of agricultural } \\
\text { products }\end{array}$ \\
\hline$a$ & $\begin{array}{l}\text { The elasticity coefficient of market } \\
\text { demand to price }\end{array}$ & $g(s)$ & $\begin{array}{l}\text { Cost function of improving green } \\
\text { degree of agricultural products }\end{array}$ \\
\hline$b$ & $\begin{array}{l}\text { The elasticity coefficient of market } \\
\text { demand to freshness }\end{array}$ & $k$ & $\begin{array}{l}\text { Sensitivity coefficient of farmer } \\
\text { cooperative to freshness of } \\
\text { agricultural products }\end{array}$ \\
\hline$p$ & Selling price of E-commerce product & $W$ & $\begin{array}{l}\text { Wholesale price of agricultural } \\
\text { products }\end{array}$ \\
\hline$\sigma$ & $\begin{array}{l}\text { The elasticity coefficient of market } \\
\text { demand to government subsidy }\end{array}$ & $d$ & Government unit subsidy price \\
\hline$q$ & $\begin{array}{l}\text { Order quantity of E-commerce } \\
\text { platform }\end{array}$ & $s$ & Green level of agricultural products \\
\hline$\beta$ & $\begin{array}{c}\text { The elasticity coefficient of market } \\
\text { demand to sales efforts }\end{array}$ & $\gamma$ & $\begin{array}{l}\text { Sensitivity coefficient of the } \\
\text { E-commerce platform to sales efforts }\end{array}$ \\
\hline
\end{tabular}

This study includes a farmer cooperative $f$ and an E-commerce platform $l$, which plays a leading role in the supply chain. Based on Liu et al. [47] and Ghosh and Shah [44] 's linear demand functions, the market demand $D$ is affected by the price $p$, the freshness of agricultural products $s$ and the sales efforts of the E-commerce platform $e$, which decreases with the price increases and increases with the freshness of agricultural products and the sales efforts of the E-commerce platform. Suppose the relationship among the three is $D=D_{0}-a p+b s+\beta e$, and $D_{0}>0, a>0, b>0, \beta>0$.

The E-commerce platform determines the sales price of agricultural products $p$ and the sales efforts $e$. The farmer cooperative determines the freshness $s$ and wholesale price $W$ of agricultural products, whose unit operating cost is $C$. According to the market demand, the suppliers decide the order quantity and assuming that there is no shortage, that is $q=D$. In order to ensure the decision variables $p, W, s$ and $e$ are positive, the relationship between the parameters should be satisfied that $\left(2 a k-b^{2}\right) \gamma-k \beta^{2}>0$ and $D_{0}-a C>0$. It is assumed that the operation cost of the E-commerce platform is not considered.

The profit of the E-commerce platform, the profit of the farmer cooperative, and the total profit of the system are expressed as follows:

The market demand of the product is

$$
q=D=D_{0}-a p+b s+\beta e
$$

The profit of the farmer cooperative is

$$
R_{f}=(W-C) q-g(s)=(W-C) q-\frac{1}{2} k s^{2}
$$

The profit of the E-commerce platform is

$$
R_{l}=(p-W) q-c(e)=(p-W) q-\frac{1}{2} \gamma e^{2}
$$


The system profit is

$$
R=R_{f}+R_{l}=(p-C) q-g(s)-c(e)=(p-C) q-\frac{1}{2} k s^{2}-\frac{1}{2} \gamma e^{2}
$$

\section{Research Models for No Government Subsidiarization}

Under the no government subsidy strategy, there are two types of decision-making modes for the E-commerce platform and the farmer cooperative: centralized decisionmaking and decentralized decision-making. Variables under the two decision-making modes are discussed as follows: The first is the price of agricultural products, the level of freshness, the sales efforts of the E-commerce platform and the profit of each entity when the E-commerce platform and the farmer cooperative make decentralized decisions. The second is the price of agricultural products, the level of freshness, the sales efforts of the E-commerce platform, and the overall profit of the supply chain when the E-commerce platform and the farmer cooperative make centralized decisions.

\subsection{The Profit Model for Decentralized Decision}

Supposed that the E-commerce platform is the decision-maker, and the farmer cooperative is the follower. The E-commerce platform determines its sales efforts $e$ and the sales price $p$ of agricultural products to meet the market demand. The farmer cooperative determines the wholesale price $W$ and freshness $s$ of agricultural products.

Under decentralized decision-making, both the E-commerce platform and the farmer cooperative make decisions based on maximizing their own interests. First, the E-commerce platform determines the sales price and sales effort of the product based on market information. Then, the farmer cooperative decides its wholesale price and freshness preservation level according to the various types of information they have.

According to the above forementioned assumption, there is

$$
p=W+\Delta p
$$

Thus, the objective functions of the E-commerce platform and the farmer cooperative are as follows:

$$
\left\{\begin{array}{l}
\max R_{f}=(W-C)\left[D_{0}-a(W+\Delta p)+b s+\beta e\right]-\frac{1}{2} k s^{2} \\
\max R_{l}=\Delta p\left[D_{0}-a(W+\Delta p)+b s+\beta e\right]-\frac{1}{2} \gamma e^{2}
\end{array}\right.
$$

The inverse induction method is used to solve the problem. First, the calculation of the first-order partial derivatives of $W$ and $s$ about $R_{f}$ in Equation (9) is below.

$$
\begin{gathered}
\frac{\partial R_{f}}{\partial W}=D_{0}+a(C-\Delta p)+b s+\beta e-2 a W \\
\frac{\partial R_{f}}{\partial s}=b(W-C)
\end{gathered}
$$

The second-order partial derivative of $W$ and $s$ about $R_{f}$ in Equation (6) is as follows.

$$
\begin{aligned}
& \frac{\partial^{2} R_{f}}{\partial W^{2}}=-2 a<0 \\
& \frac{\partial^{2} R_{f}}{\partial s^{2}}=-k<0
\end{aligned}
$$

The corresponding Hessian matrix is $H=\left(\begin{array}{cc}-2 a & b \\ b & -k\end{array}\right)$, and its first-order and second-order master sub-determinants are $\left|H_{1}\right|=-2 a<0$ and $\left|H_{2}\right|=2 a k-b^{2}>0$, 
respectively. Thus, the Hessian matrix is negative definite, and there is a unique optimal solution $(W, s)$ making the $R_{f}$ global maximal.

$$
\begin{aligned}
& \text { Let } \frac{\partial R_{f}}{\partial W}=0 \text { and } \frac{\partial R_{f}}{\partial s}=0 \text {, then } \\
& \qquad \begin{aligned}
W=\frac{D_{0}+a(C-\Delta p)+b s+\beta e}{2 a} \\
s=\frac{b(W-C)}{k}
\end{aligned}
\end{aligned}
$$

With Equations (11) and (12), the expressions of $W$ and $s$ for $\Delta P$ and $e$ are obtained as follows.

$$
\left\{\begin{array}{l}
W=\frac{k\left(D_{0}+\beta e-a \Delta p\right)+\left(a k-b^{2}\right) C}{2 a k-b^{2}} \\
s=b \frac{D_{0}+\beta e-a(C+\Delta p)}{2 a k-b^{2}}
\end{array}\right.
$$

Apply Equation (9) into Equation (6), then

$$
R_{l}=\Delta P \frac{a k\left[D_{0}+\beta e-a(C+\Delta p)\right]}{2 a k-b^{2}}-\frac{1}{2} \gamma e^{2}
$$

The first-order partial derivatives of $\Delta P$ and $e$ about $R_{l}$ in Equation (10) is below.

$$
\begin{gathered}
\frac{\partial R_{l}}{\partial \Delta p}=\frac{a k\left[D_{0}+\beta e-a(C+2 \Delta p)\right]}{2 a k-b^{2}} \\
\frac{\partial R_{l}}{\partial e}=\frac{a k \beta \Delta p}{2 a k-b^{2}}-\gamma e
\end{gathered}
$$

The second-order partial derivative of $\Delta P$ and $e$ about $R_{l}$ in Equation (10) is as follows.

$$
\begin{gathered}
\frac{\partial^{2} R_{l}}{\partial \Delta p^{2}}=\frac{-2 a^{2} k}{2 a k-b^{2}}<0 \\
\frac{\partial^{2} R_{l}}{\partial s^{2}}=-\gamma<0
\end{gathered}
$$

The corresponding Hessian matrix is $H=\left(\begin{array}{cc}\frac{-2 a^{2} k}{2 a k-b^{2}} & \frac{a k \beta}{2 a k-b^{2}} \\ \frac{a k \beta}{2 a k-b^{2}} & -\gamma\end{array}\right)$, and its first-order and second-order master sub-determinants are $\left|H_{1}\right|=\frac{-2 a k^{2}}{2 a k-b^{2}}<0$ and $\left|H_{2}\right|=\frac{a^{2} k\left[2\left(2 a k-b^{2}\right) \gamma-k \beta^{2}\right]}{\left(2 a k-b^{2}\right)^{2}}>0$, respectively. Thus, the Hessian matrix is negative definite, and there is a unique optimal solution $(\Delta p, e)$ making the $R_{l}$ global maximal.

$$
\begin{aligned}
& \text { Let } \begin{aligned}
\frac{\partial R_{l}}{\partial \Delta p}=0 \text { and } \frac{\partial R_{l}}{\partial e}=0 \text {, then } & \\
\qquad p & =\frac{D_{0}+\beta e-a C}{2 a} \\
e & =\frac{a k \beta \Delta p}{\left(2 a k-b^{2}\right) \gamma}
\end{aligned}
\end{aligned}
$$


With Equations (11) and (12), then

$$
\left\{\begin{array}{l}
\Delta p=\frac{\gamma\left(2 a k-b^{2}\right)\left(D_{0}-a C\right)}{a\left[2\left(2 a k-b^{2}\right) \gamma-k \beta^{2}\right]} \\
e_{1}^{*}=\frac{k \beta\left(D_{0}-a C\right)}{2\left(2 a k-b^{2}\right) \gamma-k \beta^{2}}
\end{array}\right.
$$

Apply Equation (13) into Equation (9), then

$$
\begin{gathered}
W_{1}{ }^{*}=\frac{k \gamma D_{0}+\left[\left(3 a k-2 b^{2}\right) \gamma-k \beta^{2}\right] C}{2\left(2 a k-b^{2}\right) \gamma-k \beta^{2}} \\
s_{1}{ }^{*}=\frac{b \gamma\left(D_{0}-a C\right)}{2\left(2 a k-b^{2}\right) \gamma-k \beta^{2}}
\end{gathered}
$$

Apply Equations (13)-(15) into Equations (1) and (5). Thus,

$$
\begin{gathered}
p_{1}^{*}=\frac{\gamma\left(3 a k-b^{2}\right) D_{0}+a\left[\left(a k-b^{2}\right) \gamma-k \beta^{2}\right] C}{a\left[2\left(2 a k-b^{2}\right) \gamma-k \beta^{2}\right]} \\
q_{1}^{*}=\frac{a k \gamma\left(D_{0}-a C\right)}{2\left(2 a k-b^{2}\right) \gamma-k \beta^{2}} \\
p_{1}^{*}=\frac{\gamma\left(3 a k-b^{2}\right) D_{0}+a\left[\left(a k-b^{2}\right) \gamma-k \beta^{2}\right] C}{a\left[2\left(2 a k-b^{2}\right) \gamma-k \beta^{2}\right]} \\
q_{1}^{*}=\frac{a k \gamma\left(D_{0}-a C\right)}{2\left(2 a k-b^{2}\right) \gamma-k \beta^{2}}
\end{gathered}
$$

The optimal profits of the E-commerce platform, the farmer cooperative and the overall system are further obtained.

$$
\begin{gathered}
R_{l 1} *=\frac{k \gamma\left(D_{0}-a C\right)^{2}}{2\left[2\left(2 a k-b^{2}\right) \gamma-k \beta^{2}\right]} \\
R_{f 1}{ }^{*}=\frac{k \gamma^{2}\left(2 a k-b^{2}\right)\left(D_{0}-a C\right)^{2}}{2\left[2\left(2 a k-b^{2}\right) \gamma-k \beta^{2}\right]^{2}} \\
R_{1}{ }^{*}=\frac{k \gamma\left[3\left(2 a k-b^{2}\right) \gamma-k \beta^{2}\right]\left(D_{0}-a C\right)^{2}}{2\left[2\left(2 a k-b^{2}\right) \gamma-k \beta^{2}\right]^{2}}
\end{gathered}
$$

\subsection{The Profit Model for Centralized Decision}

Centralized decision-making is to regard the E-commerce platform and the farmer cooperative as a consortium and make a profit maximization decision from the whole consortium. Then

$$
R=(p-C) q-\frac{1}{2} k s^{2}-\frac{1}{2} \gamma e^{2}=(p-C)\left(D_{0}-a p+b s+\beta e\right)-\frac{1}{2} k s^{2}-\frac{1}{2} \gamma e^{2}
$$

Similarly, the first-order partial derivatives of $R$ over $p, s$ and $e$ in Equation (16) are as follows.

$$
\begin{gathered}
\frac{\partial R}{\partial p}=D_{0}-2 a p+b s+\beta e \\
\frac{\partial R}{\partial s}=b(p-C)-k s \\
\frac{\partial R}{\partial e}=\beta(p-C)-\gamma e
\end{gathered}
$$


The second-order partial derivatives of $R$ over $p, s$ and $e$ in Equation (16) are as follows.

$$
\begin{gathered}
\frac{\partial^{2} R}{\partial p^{2}}=-2 a<0 \\
\frac{\partial^{2} R}{\partial s^{2}}=-k<0 \\
\frac{\partial^{2} R}{\partial e^{2}}=-\gamma<0
\end{gathered}
$$

The Hessian matrix is $H=\left(\begin{array}{ccc}-2 a & b & \beta \\ b & -k & 0 \\ \beta & 0 & -\gamma\end{array}\right)$, and its first-order and third-order master subdeterminants are $\left|H_{1}\right|=-2 a<0$ and $\left|H_{3}\right|=-\left[\left(2 a k-b^{2}\right) \gamma-k \beta^{2}\right]<0$, respectively. Thus, the Hessian matrix is negative definite, and there is a unique optimal solution $(W, s, e)$ making the $R$ global maximal.

Let $\frac{\partial R}{\partial p}=0, \frac{\partial R}{\partial s}=0$ and $\frac{\partial R}{\partial e}=0$, then

$$
\begin{gathered}
p=\frac{D_{0}+b s+\beta e}{2 a} \\
s=\frac{b(p-C)}{k} \\
e=\frac{\beta(p-C)}{\gamma}
\end{gathered}
$$

With Equations (17)-(19), it is obvious that

$$
\begin{gathered}
p_{2}{ }^{*}=\frac{k \gamma D_{0}+\left[\left(a k-b^{2}\right) \gamma-k \beta^{2}\right] C}{\left(2 a k-b^{2}\right) \gamma-k \beta^{2}} \\
s_{2}{ }^{*}=\frac{b \gamma\left(D_{0}-a C\right)}{\left(2 a k-b^{2}\right) \gamma-k \beta^{2}} \\
e_{2}{ }^{*}=\frac{k \beta\left(D_{0}-a C\right)}{\left(2 a k-b^{2}\right) \gamma-k \beta^{2}}
\end{gathered}
$$

Therefore, the optimal solution and total profit are given below.

$$
\begin{aligned}
q_{2}{ }^{*} & =\frac{a k \gamma\left(D_{0}-a C\right)}{\left(2 a k-b^{2}\right) \gamma-k \beta^{2}} \\
R_{2}{ }^{*} & =\frac{k \gamma\left(D_{0}-a C\right)^{2}}{2\left[\left(2 a k-b^{2}\right) \gamma-k \beta^{2}\right]}
\end{aligned}
$$

4.3. Comparative Analysis of the Two Decision Models

Under the non-government subsidy strategy, the decision variables of the supply chain and the profits of each subject under the two modes of decentralized decision-making and centralized decision-making are shown in Table 2.

Proposition 1. Under centralized decision-making, the sales of agricultural products $q$, the freshkeeping level $s$, and the sales efforts of the E-commerce platform e are all higher than those under decentralized decision-making. That is $q_{2}{ }^{*}>q_{1}{ }^{*}, s_{2}{ }^{*}>s_{1}{ }^{*}, e_{2}{ }^{*}>e_{1}{ }^{*}$.

Proof. $\frac{q_{1}{ }^{*}}{q_{2}{ }^{*}}=\frac{s_{1}{ }^{*}}{s_{2}{ }^{*}}=\frac{e_{1}{ }^{*}}{e_{2}{ }^{*}}=\frac{\left(2 a k-b^{2}\right) \gamma-k \beta^{2}}{2\left(2 a k-b^{2}\right) \gamma-k \beta^{2}}<1$, so $q_{2}{ }^{*}>q_{1}{ }^{*} s_{2}{ }^{*}>s_{1}{ }^{*}, e_{2}{ }^{*}>e_{1}{ }^{*}$. 
Table 2. Variable values and profits of different decision-making modes.

\begin{tabular}{ccc}
\hline Parameter & Decentralized Decision-Making & Centralized Decision-Making \\
\hline$s$ & $\frac{b \gamma\left(D_{0}-a C\right)}{2\left(2 a k-b^{2}\right) \gamma-k \beta^{2}}$ & $\frac{b \gamma\left(D_{0}-a C\right)}{\left(2 a k-b^{2}\right) \gamma-k \beta^{2}}$ \\
\hline$e$ & $\frac{k \beta\left(D_{0}-a C\right)}{2\left(2 a k-b^{2}\right) \gamma-k \beta^{2}}$ & $\frac{k \beta\left(D_{0}-a C\right)}{\left(2 a k-b^{2}\right) \gamma-k \beta^{2}}$ \\
\hline$p$ & $\frac{\gamma\left(3 a k-b^{2}\right) D_{0}+a\left[\left(a k-b^{2}\right) \gamma-k \beta^{2}\right] C}{a\left[2\left(2 a k-b^{2}\right) \gamma-k \beta^{2}\right]}$ & $\frac{k \gamma D_{0}+\left[\left(a k-b^{2}\right) \gamma-k \beta^{2}\right] C}{\left(2 a k-b^{2}\right) \gamma-k \beta^{2}}$ \\
\hline$q$ & $\frac{a k \gamma\left(D_{0}-a C\right)}{2\left(2 a k-b^{2}\right) \gamma-k \beta^{2}}$ & $\frac{a k \gamma\left(D_{0}-a C\right)}{\left(2 a k-b^{2}\right) \gamma-k \beta^{2}}$ \\
\hline$R_{f}$ & $\frac{k \gamma D_{0}+\left[\left(3 a k-2 b^{2}\right) \gamma-k \beta^{2}\right] C}{2\left(2 a k-b^{2}\right) \gamma-k \beta^{2}}$ & - \\
\hline$R_{l}$ & $\frac{k \gamma^{2}\left(2 a k-b^{2}\right)\left(D_{0}-a C\right)^{2}}{2\left[2\left(2 a k-b^{2}\right) \gamma-k \beta^{2}\right]^{2}}$ & \\
\hline$R$ & $\frac{k \gamma\left(D_{0}-a C\right)^{2}}{2\left[2\left(2 a k-b^{2}\right) \gamma-k \beta^{2}\right]}$ & $\frac{k \gamma\left(D_{0}-a C\right)^{2}}{2\left[\left(2 a k-b^{2}\right) \gamma-k \beta^{2}\right]}$ \\
\hline
\end{tabular}

Proposition 2. When $\left(a k-b^{2}\right) \gamma-k \beta^{2}>0$, under the decentralized decision, the selling price of agricultural products is higher than the centralized decision. That is $p_{1}{ }^{*}>p_{2}{ }^{*}$. When $\left(a k-b^{2}\right) \gamma-k \beta^{2}<0$, under the decentralized decision, the selling price of agricultural products is lower than the centralized decision. That is $p_{1}{ }^{*}<p_{2}{ }^{*}$.

Proof. $p_{1}{ }^{*}-p_{2}{ }^{*}=\frac{\gamma\left(2 a k-b^{2}\right)\left[\left(a k-b^{2}\right) \gamma-k \beta^{2}\right]\left(D_{0}-a C\right)}{a\left[2\left(2 a k-b^{2}\right) \gamma-k \beta^{2}\right]\left[\left(2 a k-b^{2}\right) \gamma-k \beta^{2}\right]}$

When $\left(a k-b^{2}\right) \gamma-k \beta^{2}<0, p_{1}{ }^{*}>p_{2}{ }^{*}$; while when $\left(a k-b^{2}\right) \gamma-k \beta^{2}<0, p_{1}{ }^{*}<p_{2}{ }^{*}$.

Proposition 3. Under centralized decision-making, the overall profit of the system composed of the E-commerce platform and the farmer cooperative is higher than that of decentralized decision-making. That is $R_{2}{ }^{*}>R_{1}{ }^{*}$.

Proof. $R_{1}{ }^{*}-R_{2}{ }^{*}=\frac{-k \gamma^{3}\left(2 a k-b^{2}\right)^{2}\left(D_{0}-a C\right)}{2\left[2\left(2 a k-b^{2}\right) \gamma-k \beta^{2}\right]^{2}\left[\left(2 a k-b^{2}\right) \gamma-k \beta^{2}\right]}<0$, so $R_{2}{ }^{*}>R_{1}{ }^{*}$.

\section{Research Models for Government Subsidiarization}

There are three main strategies for the government to subsidize the supply chain of agricultural products: (1) the strategy of subsidizing the farmer cooperative; (2) the strategy of subsidizing the E-commerce platform; and (3) the strategy of subsidizing customers.

\subsection{The Government's Strategy of Subsidizing the Farmer Cooperative}

Suppose that the unit price of government subsidies to the farmer cooperative is $d$, then

The profit of the farmer cooperative is $R_{f}=(W+d-C) q-\frac{1}{2} k s^{2}$

The profit of the E-commerce platform is $R_{l}=(p-W) q-\frac{1}{2} \gamma e^{2}$

The system profit is $R=R_{f}+R_{l}=(p+d-C) q-\frac{1}{2} k s^{2}-\frac{1}{2} \gamma e^{2}$ 
5.1.1. The Profit Model of Each Decision-Making Body in Decentralized Decision-Making

Under decentralized decision-making, both the E-commerce platform and the farmer cooperative make decisions based on maximizing their own interests. First, the E-commerce platform determines the sales price $p$ and sales efforts $e$ of agricultural products according to the market information. Then the farmer cooperative decides its wholesale price $W$ and freshness level $s$.

According to the reverse induction method, the decision variables of the agricultural product supply chain are below.

$$
\begin{gathered}
W_{3}{ }^{*}=\frac{k \gamma D_{0}+\left[\left(3 a k-2 b^{2}\right) \gamma-k \beta^{2}\right](C-d)}{2\left(2 a k-b^{2}\right) \gamma-k \beta^{2}} \\
s_{3}{ }^{*}=\frac{b \gamma\left[D_{0}-a(C-d)\right]}{2\left(2 a k-b^{2}\right) \gamma-k \beta^{2}} \\
p_{3}{ }^{*}=\frac{\left(3 a k D_{0}-a(C-d)\right]}{2\left(2 a k-b^{2}\right) \gamma-k \beta^{2}} \\
q_{3}^{*}=\frac{a k \gamma\left[D_{0}-a\left(C_{f}+C_{l}-d\right)\right]}{2\left(2 a k-b^{2}\right) \gamma-k \beta^{2}} \\
R_{l 3}{ }^{*}=\frac{k \gamma\left[\left(D_{0}-a(C-d) b^{2}\right) \gamma-k \beta^{2}\right](C-d)}{2\left[2\left(2 a k-b^{2}\right) \gamma-k \beta^{2}\right]} \\
R_{f 3}{ }^{*}=\frac{k \gamma^{2}\left(2 a k-b^{2}\right)\left[D_{0}-a(C-d)\right]^{2}}{2\left[2\left(2 a k-b^{2}\right) \gamma-k \beta^{2}\right]^{2}} \\
k \gamma\left[3\left(2 a k-b^{2}\right) \gamma-k \beta^{2}\right]\left[D_{0}-a(C-d)\right]^{2} \\
2\left[2\left(2 a k-b^{2}\right) \gamma-k \beta^{2}\right]^{2}
\end{gathered}
$$

5.1.2. The Profit Model of Each Decision-Making Body in Centralized Decision-Making

Under centralized decision-making, the profit of the system is

$$
R=(p+d-C)\left(D_{0}-a p+b s+\beta e\right)-\frac{1}{2} k s^{2}-\frac{1}{2} \gamma e^{2}
$$

Similarly, the decision variables and profits of the agricultural product supply chain are

$$
\begin{gathered}
p_{4}{ }^{*}=\frac{k \gamma D_{0}+\left[\left(a k-b^{2}\right) \gamma-k \beta^{2}\right](C-d)}{\left(2 a k-b^{2}\right) \gamma-k \beta^{2}} \\
s_{4}^{*}=\frac{b \gamma\left[D_{0}-a(C-d)\right]}{\left(2 a k-b^{2}\right) \gamma-k \beta^{2}} \\
e_{4}^{*}=\frac{k \beta\left[D_{0}-a(C-d)\right]}{\left(2 a k-b^{2}\right) \gamma-k \beta^{2}} \\
q_{4}^{*}=\frac{a k \gamma\left[D_{0}-a(C-d)\right]}{\left(2 a k-b^{2}\right) \gamma-k \beta^{2}} \\
R_{4}{ }^{*}=\frac{k \gamma\left[D_{0}-a(C-d)\right]^{2}}{2\left[\left(2 a k-b^{2}\right) \gamma-k \beta^{2}\right]}
\end{gathered}
$$




\subsubsection{Comparison of the Two Decision Models}

Under the strategy of government subsidizing the farmer cooperative, the decision variables of the supply chain and the profits of each subject under the two modes of decentralized decision-making and centralized decision-making are shown in Table 3.

Table 3. Variable values and profits of different decision-making modes.

\begin{tabular}{ccc}
\hline Parameter & Decentralized Decision-Making & Centralized Decision-Making \\
\hline$s$ & $\frac{b \gamma\left[D_{0}-a(C-d)\right]}{2\left(2 a k-b^{2}\right) \gamma-k \beta^{2}}$ & $\frac{b \gamma\left[D_{0}-a(C-d)\right]}{\left(2 a k-b^{2}\right) \gamma-k \beta^{2}}$ \\
\hline$e$ & $\frac{k \beta\left[D_{0}-a(C-d)\right]}{2\left(2 a k-b^{2}\right) \gamma-k \beta^{2}}$ & $\frac{k \beta\left[D_{0}-a(C-d)\right]}{\left(2 a k-b^{2}\right) \gamma-k \beta^{2}}$ \\
\hline$p$ & $\frac{\left(3 a k-b^{2}\right) \gamma D_{0}+a\left[\left(a k-b^{2}\right) \gamma-k \beta^{2}\right](C-d)}{a\left[2\left(2 a k-b^{2}\right) \gamma-k \beta^{2}\right]}$ & $\frac{k \gamma D_{0}+\left[\left(a k-b^{2}\right) \gamma-k \beta^{2}\right](C-d)}{\left(2 a k-b^{2}\right) \gamma-k \beta^{2}}$ \\
\hline$q$ & $\frac{a k \gamma\left[D_{0}-a(C-d)\right]}{2\left(2 a k-b^{2}\right) \gamma-k \beta^{2}}$ & $\frac{a k \gamma\left[D_{0}-a(C-d)\right]}{\left(2 a k-b^{2}\right) \gamma-k \beta^{2}}$ \\
\hline$W$ & $\frac{k \gamma D_{0}+\left[\left(3 a k-2 b^{2}\right) \gamma-k \beta^{2}\right](C-d)}{2\left(2 a k-b^{2}\right) \gamma-k \beta^{2}}$ & - \\
\hline$R_{l}$ & $\frac{k \gamma\left[D_{0}-a(C-d)\right]^{2}}{2\left[2\left(2 a k-b^{2}\right) \gamma-k \beta^{2}\right]}$ & - \\
\hline$R_{f}$ & $\frac{k \gamma^{2}\left(2 a k-b^{2}\right)\left[D_{0}-a(C-d)\right]^{2}}{2\left[2\left(2 a k-b^{2}\right) \gamma-k \beta^{2}\right]^{2}}$ & \\
\hline$R$ & $\frac{k \gamma\left[3\left(2 a k-b^{2}\right) \gamma-k \beta^{2}\right]\left[D_{0}-a(C-d)\right]^{2}}{2\left[2\left(2 a k-b^{2}\right) \gamma-k \beta^{2}\right]^{2}}$ & $\frac{k \gamma\left[D_{0}-a(C-d)\right]^{2}}{2\left[\left(2 a k-b^{2}\right) \gamma-k \beta^{2}\right]}$ \\
\hline \multirow{2}{*}{$R$} & &
\end{tabular}

$$
\begin{aligned}
& \frac{s_{3}{ }^{*}}{s_{4}{ }^{*}}=\frac{e_{3}{ }^{*}}{e_{4}{ }^{*}}=\frac{q_{3}{ }^{*}}{q_{4}{ }^{*}}=\frac{\left(2 a k-b^{2}\right) \gamma-k \beta^{2}}{2\left(2 a k-b^{2}\right) \gamma-k \beta^{2}}<1, \text { so } s_{3}{ }^{*}<s_{4}{ }^{*}, e_{3}{ }^{*}<e_{4}{ }^{*}, q_{3}{ }^{*}<q_{4}{ }^{*} \\
& p_{3}{ }^{*}-p_{4}^{*}=\frac{\gamma\left(2 a k-b^{2}\right)\left[\left(a k-b^{2}\right) \gamma-k \beta^{2}\right]\left[D_{0}-a(C-d)\right]}{a\left[2\left(2 a k-b^{2}\right) \gamma-k \beta^{2}\right]\left[\left(2 a k-b^{2}\right) \gamma-k \beta^{2}\right]} \\
& R_{3}{ }^{*}-R_{4}{ }^{*}=-\frac{k \gamma^{3}\left(2 a k-b^{2}\right)^{2}\left[D_{0}-a(C-d)\right]^{2}}{2\left[2\left(2 a k-b^{2}\right) \gamma-k \beta^{2}\right]^{2}\left[\left(2 a k-b^{2}\right) \gamma-k \beta^{2}\right]}<0 \text {, so } R_{3}{ }^{*}<R_{4}{ }^{*}
\end{aligned}
$$

From the calculation in Table 3, it can be seen that, as with no government subsidy, when the government subsidizes the farmer cooperative, under the centralized decisionmaking, the sales of agricultural products, the freshness level and the sales efforts of the E-commerce platform are all higher than those of the decentralized decision-making. That is $q_{4}{ }^{*}>q_{3}{ }^{*}, s_{4}{ }^{*}>s_{3}{ }^{*}, e_{4}{ }^{*}>e_{3}{ }^{*}$. When $\left(a k-b^{2}\right) \gamma-k \beta^{2}>0$, under the decentralized decision, the selling price of agricultural products is higher than the centralized decision. That is $p_{3}{ }^{*}>p_{4}{ }^{*}$. When $\left(a k-b^{2}\right) \gamma-k \beta^{2}<0$, under the decentralized decision, the selling price of agricultural products is lower than the centralized decision. That is $p_{3}{ }^{*}<p_{4}{ }^{*}$. Under centralized decision-making, the overall profit of the system is higher than that of decentralized decision-making. That is $R_{3}{ }^{*}<R_{4}{ }^{*}$. Therefore, on the whole, centralized decision-making is better than decentralized decision-making.

\subsection{The Government's Strategy of Subsidizing the E-Commerce Platform}

Suppose that the unit price of the E-commerce platform subsidized by the government is $d$, then the profits of each member and the system profit are as follows.

The profit of the farmer cooperative is $R_{f}=(W-C) q-\frac{1}{2} k s^{2}$

The profit of the E-commerce platform is $R_{l}=(p+d-W) q-\frac{1}{2} \gamma e^{2}$

The system profit is $R=R_{f}+R_{l}=(p+d-C) q-\frac{1}{2} k s^{2}-\frac{1}{2} \gamma e^{2}$ 
5.2.1. The Profit Model of Each Decision-Making Body in Decentralized Decision-Making

Similarly, under decentralized decision-making, both the E-commerce platform and the farmer cooperative make decisions based on maximizing their own interests. First, the E-commerce platform determines the sales price $p$ and sales efforts $e$ of agricultural products according to the market information. The farmer cooperative then decides its wholesale price $W$ and freshness level $s$.

According to the reverse induction method, the decision variables of the agricultural product supply chain are

$$
\begin{gathered}
W_{5}{ }^{*}=\frac{k \gamma\left(D_{0}+a d\right)+\left[\left(3 a k-2 b^{2}\right) \gamma-k \beta^{2}\right] C}{2\left(2 a k-b^{2}\right) \gamma-k \beta^{2}} \\
s_{5}{ }^{*}=\frac{b \gamma\left[D_{0}-a(C-d)\right]}{2\left(2 a k-b^{2}\right) \gamma-k \beta^{2}} \\
p_{5}{ }^{*}=\frac{k \beta\left[D_{0}-a(C-d)\right]}{2\left(2 a k-b^{2}\right) \gamma-k \beta^{2}} \\
q_{5}^{*}=\frac{a k \gamma\left[D_{0}-a(C-d)\right]}{2\left(2 a k-b^{2}\right) \gamma-k \beta^{2}} \\
R_{l 5}{ }^{*}=\frac{\left.b^{2}\right) \gamma D_{0}+a\left[\left(a k-b^{2}\right) \gamma-k \beta^{2}\right](C-a(C-d)]^{2}}{2\left[2\left(2 a k-b^{2}\right) \gamma-k \beta^{2}\right]} \\
R_{f 5}{ }^{*}=\frac{k \gamma^{2}\left(2 a k-b^{2}\right)\left[D_{0}-a(C-d)\right]^{2}}{2\left[2\left(2 a k-b^{2}\right) \gamma-k \beta^{2}\right]^{2}} \\
k \gamma\left[3\left(2 a k-b^{2}\right) \gamma-k \beta^{2}\right]\left[D_{0}-a(C-d)\right]^{2} \\
2\left[2\left(2 a k-b^{2}\right) \gamma-k \beta^{2}\right]^{2}
\end{gathered}
$$

5.2.2. The Profit Model of Each Decision-Making Body in Centralized Decision-Making Under centralized decision-making, the profit of the system is

$$
R=(p+d-C)\left(D_{0}-a p+b s+\beta e\right)-\frac{1}{2} k s^{2}-\frac{1}{2} \gamma e^{2}
$$

This decision is the same as the government subsidizing the farmer cooperative.

$$
\begin{gathered}
p_{6}{ }^{*}=\frac{k \gamma D_{0}+\left[\left(a k-b^{2}\right) \gamma-k \beta^{2}\right](C-d)}{\left(2 a k-b^{2}\right) \gamma-k \beta^{2}} \\
s_{4}^{*}=\frac{b \gamma\left[D_{0}-a(C-d)\right]}{\left(2 a k-b^{2}\right) \gamma-k \beta^{2}} \\
e_{4}^{*}=\frac{k \beta\left[D_{0}-a(C-d)\right]}{\left(2 a k-b^{2}\right) \gamma-k \beta^{2}} \\
q_{4}^{*}=\frac{a k \gamma\left[D_{0}-a(C-d)\right]}{\left(2 a k-b^{2}\right) \gamma-k \beta^{2}} \\
R_{4}{ }^{*}=\frac{k \gamma\left[D_{0}-a(C-d)\right]^{2}}{2\left[\left(2 a k-b^{2}\right) \gamma-k \beta^{2}\right]}
\end{gathered}
$$


5.2.3. Comparison of the Two Strategies of the Government to Subsidize the Farmer Cooperative and the E-Commerce Platform

Proposition 4. Under the two strategies of government subsidies, the farmer cooperative and government subsidies, the E-commerce platform accepts that the wholesale price of agricultural products is affected differently by the subsidy object; other variables are the same. That is $s_{3}{ }^{*}=s_{5}{ }^{*}$, $e_{3}{ }^{*}=e_{5}{ }^{*}$ and $p_{3}{ }^{*}=p_{5}{ }^{*}$. The profits of all decision-makers and the total profits of the supply chain are the same. That is $R_{f 3}{ }^{*}=R_{f 5}{ }^{*}, R_{l 3}{ }^{*}=R_{l 5}{ }^{*}$ and $R_{3}{ }^{*}=R_{5}{ }^{*}$.

Proposition 5. Under the two strategies of government subsidies to the farmer cooperative and government subsidies to the E-commerce platform, the decision variables, and the total profit of the supply chain in centralized decision-making are the same. That is $s_{4}{ }^{*}=s_{6}{ }^{*}, e_{4}{ }^{*}=e_{6}{ }^{*}, p_{4}{ }^{*}=p_{6}{ }^{*}$ and $R_{4}{ }^{*}=R_{6}{ }^{*}$.

\subsection{The Government's Strategy of Subsidizing Consumers}

Suppose the unit price of government subsidies is $d$, then the market demand of agricultural products is $q=D=D_{0}-a p+b s+\beta e+\sigma d$ [48]. Consumers' sensitivity to agricultural product prices is higher than the sensitivity to government price subsidies. That is $a>\sigma$.

The profit of the farmer cooperative is $R_{f}=(W-C) q-\frac{1}{2} k s^{2}$

The profit of the E-commerce platform is $R_{l}=(p-W) q-\frac{1}{2} \gamma e^{2}$

The system profit is $R=R_{f}+R_{l}=(p-C) q-\frac{1}{2} k s^{2}-\frac{1}{2} \gamma e^{2}$

5.3.1. The Profit Model of Each Decision-Making Body in Decentralized Decision-Making

Similarly, under decentralized decision-making, both the E-commerce platform and the farmer cooperative make decisions based on maximizing their own interests. First, the E-commerce platform determines the sales price $p$ and sales efforts $e$ of agricultural products according to the market information. The farmer cooperative then decides its wholesale price $W$ and freshness level $s$.

According to the reverse induction method, the decision variables of the agricultural product supply chain are:

$$
\begin{aligned}
& W_{7}^{*}=\frac{k \gamma\left(D_{0}+\sigma d\right)+\left[\left(3 a k-2 b^{2}\right) \gamma-k \beta^{2}\right] C}{2\left(2 a k-b^{2}\right) \gamma-k \beta^{2}} \\
& s_{7}^{*}=\frac{b \gamma\left(D_{0}+\sigma d-a C\right)}{2\left(2 a k-b^{2}\right) \gamma-k \beta^{2}} \\
& e_{7}^{*}=\frac{k \beta\left(D_{0}+\sigma d-a C\right)}{2\left(2 a k-b^{2}\right) \gamma-k \beta^{2}} \\
& p_{7}^{*}=\frac{\left(3 a k-b^{2}\right) \gamma\left(D_{0}+\sigma d\right)+\left[\left(a k-b^{2}\right) \gamma-k \beta^{2}\right] a C}{a\left[2\left(2 a k-b^{2}\right) \gamma-k \beta^{2}\right]} \\
& q_{7}^{*}=\frac{a k \gamma\left(D_{0}+\sigma d-a C\right)}{2\left(2 a k-b^{2}\right) \gamma-k \beta^{2}} \\
& R_{l 7}^{*}=\frac{k \gamma\left(D_{0}+\sigma d-a C\right)^{2}}{2\left[2\left(2 a k-b^{2}\right) \gamma-k \beta^{2}\right]} \\
& R_{f 7} *=\frac{k \gamma^{2}\left(2 a k-b^{2}\right)\left(D_{0}+\sigma d-a C\right)^{2}}{2\left[2\left(2 a k-b^{2}\right) \gamma-k \beta^{2}\right]^{2}} \\
& R_{7}^{*}=\frac{k \gamma\left[3\left(2 a k-b^{2}\right) \gamma-k \beta^{2}\right]\left(D_{0}+\sigma d-a C\right)^{2}}{2\left[2\left(2 a k-b^{2}\right) \gamma-k \beta^{2}\right]^{2}}
\end{aligned}
$$


5.3.2. The Profit Model of Each Decision-Making Body in Centralized Decision-Making Under centralized decision-making, the profit of the system is

$$
R=(p-C)\left(D_{0}-a p+b s+\beta e+\sigma d\right)-\frac{1}{2} k s^{2}-\frac{1}{2} \gamma e^{2}
$$

Similarly, the decision variables and profits of the agricultural product supply chain are

$$
\begin{gathered}
p_{8}^{*}=\frac{k \gamma\left(D_{0}+\sigma d\right)+\left[\left(a k-b^{2}\right) \gamma-k \beta^{2}\right] C}{\left(2 a k-b^{2}\right) \gamma-k \beta^{2}} \\
s_{8}^{*}=\frac{b \gamma\left(D_{0}+\sigma d-a C\right)}{\left(2 a k-b^{2}\right) \gamma-k \beta^{2}} \\
e_{8}^{*}=\frac{k \beta\left(D_{0}+\sigma d-a C\right)}{\left(2 a k-b^{2}\right) \gamma-k \beta^{2}} \\
q_{8}^{*}=\frac{a k \gamma\left(D_{0}+\sigma d-a C\right)}{\left(2 a k-b^{2}\right) \gamma-k \beta^{2}} \\
R_{8}^{*}=\frac{k \gamma\left(D_{0}+\sigma d-a C\right)^{2}}{2\left[\left(2 a k-b^{2}\right) \gamma-k \beta^{2}\right]}
\end{gathered}
$$

\begin{tabular}{|c|c|c|}
\hline Parameter & Decentralized Decision-Making & Centralized Decision-Making \\
\hline$s$ & $\frac{b \gamma\left(D_{0}+\sigma d-a C\right)}{2\left(2 a k-b^{2}\right) \gamma-k \beta^{2}}$ & $\frac{b \gamma\left(D_{0}+\sigma d-a C\right)}{\left(2 a k-b^{2}\right) \gamma-k \beta^{2}}$ \\
\hline$e$ & $\frac{k \beta\left(D_{0}+\sigma d-a C\right)}{2\left(2 a k-b^{2}\right) \gamma-k \beta^{2}}$ & $\frac{k \beta\left(D_{0}+\sigma d-a C\right)}{\left(2 a k-b^{2}\right) \gamma-k \beta^{2}}$ \\
\hline$p$ & $\frac{\left(3 a k-b^{2}\right) \gamma\left(D_{0}+\sigma d\right)+\left[\left(a k-b^{2}\right) \gamma-k \beta^{2}\right] a C}{a\left[2\left(2 a k-b^{2}\right) \gamma-k \beta^{2}\right]}$ & $\frac{k \gamma\left(D_{0}+\sigma d\right)+\left[\left(a k-b^{2}\right) \gamma-k \beta^{2}\right] C}{\left(2 a k-b^{2}\right) \gamma-k \beta^{2}}$ \\
\hline$q$ & $\frac{a k \gamma\left(D_{0}+\sigma d-a C\right)}{2\left(2 a k-b^{2}\right) \gamma-k \beta^{2}}$ & $\frac{a k \gamma\left(D_{0}+\sigma d-a C\right)}{\left(2 a k-b^{2}\right) \gamma-k \beta^{2}}$ \\
\hline$W$ & $\frac{k \gamma\left(D_{0}+\sigma d\right)+\left[\left(3 a k-2 b^{2}\right) \gamma-k \beta^{2}\right] C}{2\left(2 a k-b^{2}\right) \gamma-k \beta^{2}}$ & - \\
\hline$R_{l}$ & $\frac{k \gamma\left(D_{0}+\sigma d-a C\right)^{2}}{2\left[2\left(2 a k-b^{2}\right) \gamma-k \beta^{2}\right]}$ & - \\
\hline$R_{f}$ & $\frac{k \gamma^{2}\left(2 a k-b^{2}\right)\left(D_{0}+\sigma d-a C\right)^{2}}{2\left[2\left(2 a k-b^{2}\right) \gamma-k \beta^{2}\right]^{2}}$ & - \\
\hline$R$ & $\frac{k \gamma\left[3\left(2 a k-b^{2}\right) \gamma-k \beta^{2}\right]\left(D_{0}+\sigma d-a C\right)^{2}}{2\left[2\left(2 a k-b^{2}\right) \gamma-k \beta^{2}\right]^{2}}$ & $\frac{k \gamma\left(D_{0}+\sigma d-a C\right)^{2}}{2\left[\left(2 a k-b^{2}\right) \gamma-k \beta^{2}\right]}$ \\
\hline $\begin{array}{l}\frac{s_{7}^{*}}{s_{8}^{*}}= \\
p_{7}^{*}-1 \\
R_{7}^{*}-\end{array}$ & $\begin{array}{l}\frac{e_{7}^{*}}{e_{8}{ }^{*}}=\frac{q_{7}^{*}}{q_{8}^{*}}=\frac{\left(2 a k-b^{2}\right) \gamma-k \beta^{2}}{2\left(2 a k-b^{2}\right) \gamma-k \beta^{2}}<1, \text { so } s_{7} \\
p_{8}{ }^{*}=\frac{\gamma\left(2 a k-b^{2}\right)\left[\left(a k-b^{2}\right) \gamma-k \beta^{2}\right]\left(D_{0}+\right.}{a\left[2\left(2 a k-b^{2}\right) \gamma-k \beta^{2}\right]\left[\left(2 a k-b^{2}\right) \gamma\right.} \\
R_{8}{ }^{*}=\frac{-k \gamma^{3}\left(2 a k-b^{2}\right)^{2}\left(D_{0}+\sigma d-a C\right)}{2\left[2\left(2 a k-b^{2}\right) \gamma-k \beta^{2}\right]^{2}\left[\left(2 a k-b^{2}\right) \gamma-\right.}\end{array}$ & $\begin{array}{l}<s_{8}^{*}, e_{7}^{*}<e_{8}^{*}, q_{7}^{*}<q_{8}^{*} \\
\frac{\sigma d-a C)}{\left.-k \beta^{2}\right]} \\
\frac{\left.k \beta^{2}\right]}{2}<0\end{array}$ \\
\hline
\end{tabular}

\subsubsection{Comparison of the Two Decision Models}

Under the strategy of government subsidizing customers, the decision variables of the supply chain and the profits of each subject under the two modes of decentralized decision-making and centralized decision-making are shown in Table 4.

Table 4. Variable values and profits of different decision-making modes. 
Hence, $R_{7}{ }^{*}<R_{8}{ }^{*}$.

From the calculation in Table 4, it can be seen that, as with no government subsidy and other government subsidies, when the government subsidizes customers, under the centralized decision-making, the sales of agricultural products, the freshness level and the sales efforts of the E-commerce platform are all higher than those of the decentralized decision-making. That is $q_{8}{ }^{*}>q_{7^{*}}, s_{8}{ }^{*}>s_{7}{ }^{*}, e_{8}{ }^{*}>e_{7}{ }^{*}$. When $\left(a k-b^{2}\right) \gamma-k \beta^{2}>$ 0 , under the decentralized decision, the selling price of agricultural products is higher than the centralized decision, that is, $p_{7}{ }^{*}>p_{8}{ }^{*}$. When $\left(a k-b^{2}\right) \gamma-k \beta^{2}<0$, under the decentralized decision, the selling price of agricultural products is lower than the centralized decision, which means that $p_{7}{ }^{*}<p_{8}{ }^{*}$. Under centralized decision-making, the overall profit of the system is higher than that of decentralized decision-making, which is $R_{8}{ }^{*}>R_{7}^{*}$.

Therefore, on the whole, centralized decision-making is better than decentralized decision-making. That is, regardless of whether there are government subsidies and how the government subsidies are used, centralized decision-making is generally better than decentralized decision-making.

\section{Research Design for the Comparative Analysis}

Since the effect of government subsidies to the farmer cooperative is almost the same as that of government subsidies to the E-commerce platform, government subsidy strategies essentially include government subsidies to the farmer cooperative and government subsidies to consumers. By comparing the effects of the supply chain under the three strategies of no government subsidy, government subsidy to farmer cooperatives and subsidy to consumers, a decision can be made about whether to subsidize and how to subsidize.

\subsection{Comparison of Supply Chain Decision Variables and Profits in Decentralized Decision-Making}

When making decentralized decisions, under the three strategies of no government subsidies, government subsidies for the farmer cooperative and government subsidies for consumers, the decision variables of the supply chain and the profits of each subject are shown in Table 5.

$$
\begin{aligned}
& \text { so } s_{3}{ }^{*}>s_{7}{ }^{*}>s_{1}{ }^{*} \text {. } \\
& e_{3}{ }^{*}-e_{7}{ }^{*}=\frac{k \beta(a-\sigma) d}{2\left(2 a k-b^{2}\right) \gamma-k \beta^{2}}>0, e_{7}{ }^{*}-e_{1}{ }^{*}=\frac{k \beta \sigma d}{2\left(2 a k-b^{2}\right) \gamma-k \beta^{2}}>0, \\
& \text { so } e_{3}{ }^{*}>e_{7}{ }^{*}>e_{1}{ }^{*} \text {. } \\
& p_{7}{ }^{*}-p_{1}{ }^{*}=\frac{\left(3 a k-b^{2}\right) \gamma \sigma d}{a\left[2\left(2 a k-b^{2}\right) \gamma-k \beta^{2}\right]}>0, p_{1}{ }^{*}-p_{3}{ }^{*}=\frac{d\left[\left(a k-b^{2}\right) \gamma-k \beta^{2}\right]}{2\left(2 a k-b^{2}\right) \gamma-k \beta^{2}} \\
& p_{7}{ }^{*}-p_{3}{ }^{*}=\frac{\left(3 a k-b^{2}\right) \gamma \sigma d+a\left[\left(a k-b^{2}\right) \gamma-k \beta^{2}\right] d}{a\left[2\left(2 a k-b^{2}\right) \gamma-k \beta^{2}\right]}>0
\end{aligned}
$$

when $\left(a k-b^{2}\right) \gamma-k \beta^{2}>0, p_{7}{ }^{*}>p_{1}{ }^{*}>p_{3}{ }^{*}$; while when $\left(a k-b^{2}\right) \gamma-k \beta^{2}<0$, $p_{7}{ }^{*}>p_{3}{ }^{*}>p_{1}{ }^{*}$.

$$
q_{3}{ }^{*}-q_{7}^{*}=\frac{a k \gamma(a-\sigma) d}{2\left(2 a k-b^{2}\right) \gamma-k \beta^{2}}>0, q_{7}^{*}-q_{1}^{*}=\frac{a k \gamma \sigma d}{2\left(2 a k-b^{2}\right) \gamma-k \beta^{2}}>0,
$$
so $q_{3}{ }^{*}>q_{7}{ }^{*}>q_{1}{ }^{*}$

$$
R_{l 3}{ }^{*}-R_{l 7} *=\frac{k \gamma(a-\sigma) d\left[2\left(D_{0}-a C\right)+(a+\sigma) d\right]}{2\left[2\left(2 a k-b^{2}\right) \gamma-k \beta^{2}\right]}>0,
$$




$$
\begin{gathered}
R_{l 7^{*}-} R_{l 1}{ }^{*}=\frac{k \gamma \sigma d\left[2\left(D_{0}-a C\right)+\sigma d\right]}{2\left[2\left(2 a k-b^{2}\right) \gamma-k \beta^{2}\right]}>0, \text { so } R_{l 3}{ }^{*}>R_{l 7^{*}}>R_{l 1}{ }^{*} \\
R_{f 3}{ }^{*}-R_{f 7}{ }^{*}=\frac{k \gamma^{2}(a-\sigma) d\left(2 a k-b^{2}\right)\left[2\left(D_{0}-a C\right)+(a+\sigma) d\right]}{2\left[2\left(2 a k-b^{2}\right) \gamma-k \beta^{2}\right]^{2}}>0 \\
R_{f 7}{ }^{*}-R_{f 1}{ }^{*}=\frac{k \gamma^{2} \sigma d\left(2 a k-b^{2}\right)\left[2\left(D_{0}-a C\right)+\sigma d\right]}{2\left[2\left(2 a k-b^{2}\right) \gamma-k \beta^{2}\right]^{2}}>0
\end{gathered}
$$

so $R_{f 3}{ }^{*}>R_{f 7}{ }^{*}>R_{f 1}{ }^{*}$.

$$
\begin{gathered}
R_{3}{ }^{*}-R_{7}{ }^{*}=\frac{k \gamma a d\left[3\left(2 a k-b^{2}\right) \gamma-k \beta^{2}\right]\left[2\left(D_{0}-a C\right)+(a+\sigma) d\right]}{2\left[2\left(2 a k-b^{2}\right) \gamma-k \beta^{2}\right]^{2}}>0, \\
R_{7}{ }^{*}-R_{1}^{*}=\frac{k \gamma \sigma d\left[3\left(2 a k-b^{2}\right) \gamma-k \beta^{2}\right]\left[2\left(D_{0}-a C\right)+\sigma d\right]}{2\left[2\left(2 a k-b^{2}\right) \gamma-k \beta^{2}\right]^{2}}>0,
\end{gathered}
$$

then $R_{3}{ }^{*}>R_{7}^{*}>R_{1}^{*}$.

Table 5. Comparison of three strategies in decentralized decision.

\begin{tabular}{cccc}
\hline Parameter & No Government Subsidy & $\begin{array}{c}\text { Government Subsidizing Farmer } \\
\text { Cooperative }\end{array}$ & Government Subsidizing Consumers \\
\hline$s$ & $\frac{b \gamma\left[D_{0}-a(C-d)\right]}{2\left(2 a k-b^{2}\right) \gamma-k \beta^{2}}$ & $\frac{b \gamma\left[D_{0}-a(C-d)\right]}{2\left(2 a k-b^{2}\right) \gamma-k \beta^{2}}$ & $\frac{b \gamma\left(D_{0}+\sigma d-a C\right)}{2\left(2 a k-b^{2}\right) \gamma-k \beta^{2}}$ \\
\hline$e$ & $\frac{k \beta\left(D_{0}-a C\right)}{2\left(2 a k-b^{2}\right) \gamma-k \beta^{2}}$ & $\frac{k \beta\left[D_{0}-a(C-d)\right]}{2\left(2 a k-b^{2}\right) \gamma-k \beta^{2}}$ & $\frac{k \beta\left(D_{0}+\sigma d-a C\right)}{2\left(2 a k-b^{2}\right) \gamma-k \beta^{2}}$ \\
\hline$p$ & $\frac{\left(3 a k-b^{2}\right) \gamma D_{0}+a\left[\left(a k-b^{2}\right) \gamma-k \beta^{2}\right] C}{a\left[2\left(2 a k-b^{2}\right) \gamma-k \beta^{2}\right]}$ & $\frac{\left(3 a k-b^{2}\right) \gamma D_{0}+a\left[\left(a k-b^{2}\right) \gamma-k \beta^{2}\right](C-d)}{a\left[2\left(2 a k-b^{2}\right) \gamma-k \beta^{2}\right]}$ & $\frac{\left(3 a k-b^{2}\right) \gamma\left(D_{0}+\sigma d\right)+\left[\left(a k-b^{2}\right) \gamma-k \beta^{2}\right] a C}{a\left[2\left(2 a k-b^{2}\right) \gamma-k \beta^{2}\right]}$ \\
\hline$q$ & $\frac{a k \gamma\left(D_{0}-a C\right)}{2\left(2 a k-b^{2}\right) \gamma-k \beta^{2}}$ & $\frac{a k \gamma\left[D_{0}-a(C-d)\right]}{2\left(2 a k-b^{2}\right) \gamma-k \beta^{2}}$ & $\frac{a k \gamma\left(D_{0}+\sigma d-a C\right)}{2\left(2 a k-b^{2}\right) \gamma-k \beta^{2}}$ \\
\hline$W$ & $\frac{k \gamma D_{0}+\left[\left(3 a k-2 b^{2}\right) \gamma-k \beta^{2}\right] C}{2\left(2 a k-b^{2}\right) \gamma-k \beta^{2}}$ & $\frac{k \gamma D_{0}+\left[\left(3 a k-2 b^{2}\right) \gamma-k \beta^{2}\right](C-d)}{2\left(2 a k-b^{2}\right) \gamma-k \beta^{2}}$ & $\frac{k \gamma\left(D_{0}+\sigma d\right)+\left[\left(3 a k-2 b^{2}\right) \gamma-k \beta^{2}\right] C}{2\left(2 a k-b^{2}\right) \gamma-k \beta^{2}}$ \\
\hline$R_{l}$ & $\frac{k \gamma\left(D_{0}-a C\right)^{2}}{2\left[2\left(2 a k-b^{2}\right) \gamma-k \beta^{2}\right]}$ & $\frac{k \gamma\left[D_{0}-a(C-d)\right]^{2}}{2\left[2\left(2 a k-b^{2}\right) \gamma-k \beta^{2}\right]}$ & $\frac{k \gamma\left(D_{0}+\sigma d-a C\right)^{2}}{2\left[2\left(2 a k-b^{2}\right) \gamma-k \beta^{2}\right]}$ \\
\hline$R_{f}$ & $\frac{k \gamma^{2}\left(2 a k-b^{2}\right)\left(D_{0}-a C\right)^{2}}{2\left[2\left(2 a k-b^{2}\right) \gamma-k \beta^{2}\right]^{2}}$ & $\frac{k \gamma^{2}\left(2 a k-b^{2}\right)\left[D_{0}-a(C-d)\right]^{2}}{2\left[2\left(2 a k-b^{2}\right) \gamma-k \beta^{2}\right]^{2}}$ & $\frac{k \gamma^{2}\left(2 a k-b^{2}\right)\left(D_{0}+\sigma d-a C\right)^{2}}{2\left[2\left(2 a k-b^{2}\right) \gamma-k \beta^{2}\right]^{2}}$ \\
\hline$R$ & $\frac{k \gamma\left[3\left(2 a k-b^{2}\right) \gamma-k \beta^{2}\right]\left(D_{0}-a C\right)^{2}}{2\left[2\left(2 a k-b^{2}\right) \gamma-k \beta^{2}\right]^{2}}$ & $\frac{k \gamma\left[3\left(2 a k-b^{2}\right) \gamma-k \beta^{2}\right]\left[D_{0}-a(C-d)\right]^{2}}{2\left[2\left(2 a k-b^{2}\right) \gamma-k \beta^{2}\right]^{2}}$ & $\frac{k \gamma\left[3\left(2 a k-b^{2}\right) \gamma-k \beta^{2}\right]\left(D_{0}+\sigma d-a C\right)^{2}}{2\left[2\left(2 a k-b^{2}\right) \gamma-k \beta^{2}\right]^{2}}$ \\
\hline
\end{tabular}

From the calculation and analysis in Table 5, it can be seen that in decentralized decision-making, compared with no government subsidies and government subsidies to consumers, the policy of subsidizing the farmer cooperative has the highest level of agricultural product preservation, sales efforts of the E-commerce platform and sales volume, and the decision-making bodies' profits and the overall supply chain profit are also the highest.

\subsection{Comparison of Supply Chain Decision Variables and Profits in Centralized Decision-Making}

In relation to making centralized decisions, under the three strategies of no government subsidies, government subsidies for the farmer cooperative, and government subsidies for consumers, the decision variables of the supply chain and the overall profits are shown in Table 6. 
Table 6. Comparison of three strategies in centralized decision-making.

\begin{tabular}{cccc}
\hline Parameter & No Government Subsidy & $\begin{array}{c}\text { Government Subsidizing Farmer } \\
\text { Cooperative }\end{array}$ & $\begin{array}{c}\text { Government Subsidizing } \\
\text { Consumers }\end{array}$ \\
\hline$s$ & $\frac{b \gamma\left(D_{0}-a C\right)}{\left(2 a k-b^{2}\right) \gamma-k \beta^{2}}$ & $\frac{b \gamma\left[D_{0}-a(C-d)\right]}{\left(2 a k-b^{2}\right) \gamma-k \beta^{2}}$ & $\frac{b \gamma\left(D_{0}+\sigma d-a C\right)}{\left(2 a k-b^{2}\right) \gamma-k \beta^{2}}$ \\
\hline$e$ & $\frac{k \beta\left(D_{0}-a C\right)}{\left(2 a k-b^{2}\right) \gamma-k \beta^{2}}$ & $\frac{k \beta\left[D_{0}-a(C-d)\right]}{\left(2 a k-b^{2}\right) \gamma-k \beta^{2}}$ & $\frac{k \beta\left(D_{0}+\sigma d-a C\right)}{\left(2 a k-b^{2}\right) \gamma-k \beta^{2}}$ \\
\hline$p$ & $\frac{k \gamma D_{0}+\left[\left(a k-b^{2}\right) \gamma-k \beta^{2}\right] C}{\left(2 a k-b^{2}\right) \gamma-k \beta^{2}}$ & $\frac{k \gamma D_{0}+\left[\left(a k-b^{2}\right) \gamma-k \beta^{2}\right](C-d)}{\left(2 a k-b^{2}\right) \gamma-k \beta^{2}}$ & $\frac{k \gamma\left(D_{0}+\sigma d\right)+\left[\left(a k-b^{2}\right) \gamma-k \beta^{2}\right] C}{\left(2 a k-b^{2}\right) \gamma-k \beta^{2}}$ \\
\hline$q$ & $\frac{a k \gamma\left[D_{0}-a(C-d)\right]}{\left(2 a k-b^{2}\right) \gamma-k \beta^{2}}$ & $\frac{a k \gamma\left[D_{0}-a(C-d)\right]}{\left(2 a k-b^{2}\right) \gamma-k \beta^{2}}$ & $\frac{a k \gamma\left(D_{0}+\sigma d-a C\right)}{\left(2 a k-b^{2}\right) \gamma-k \beta^{2}}$ \\
\hline$R$ & $\frac{k \gamma\left(D_{0}-a C\right)^{2}}{2\left[\left(2 a k-b^{2}\right) \gamma-k \beta^{2}\right]}$ & $\frac{k \gamma\left[D_{0}-a(C-d)\right]^{2}}{2\left[\left(2 a k-b^{2}\right) \gamma-k \beta^{2}\right]}$ & $\frac{k \gamma\left(D_{0}+\sigma d-a C\right)^{2}}{2\left[\left(2 a k-b^{2}\right) \gamma-k \beta^{2}\right]}$ \\
\hline
\end{tabular}

$$
s_{4}{ }^{*}-s_{8}{ }^{*}=\frac{b \gamma(a-\sigma) d}{\left(2 a k-b^{2}\right) \gamma-k \beta^{2}}>0, s_{8}{ }^{*}-s_{2}{ }^{*}=\frac{b \gamma \sigma d}{\left(2 a k-b^{2}\right) \gamma-k \beta^{2}}>0,
$$

then $s_{4}{ }^{*}>s_{8}{ }^{*}>s_{2}{ }^{*}$.

$$
e_{4}{ }^{*}-e_{8}{ }^{*}=\frac{k \beta(a-\sigma) d}{\left(2 a k-b^{2}\right) \gamma-k \beta^{2}}>0, e_{8}{ }^{*}-e_{2}{ }^{*}=\frac{b \gamma \sigma d}{\left(2 a k-b^{2}\right) \gamma-k \beta^{2}}>0,
$$

hence $e_{4}{ }^{*}>e_{8}{ }^{*}>e_{2}{ }^{*}$.

$$
\begin{aligned}
p_{8}^{*}-p_{2}{ }^{*}= & \frac{\sigma d k \gamma}{\left(2 a k-b^{2}\right) \gamma-k \beta^{2}}>0, p_{2}{ }^{*}-p_{4}{ }^{*}=\frac{\left[\left(a k-b^{2}\right) \gamma-k \beta^{2}\right] d}{\left(2 a k-b^{2}\right) \gamma-k \beta^{2}} \\
& p_{8}{ }^{*}-p_{4}{ }^{*}=\frac{\sigma d k \gamma+\left[\left(a k-b^{2}\right) \gamma-k \beta^{2}\right] d}{\left(2 a k-b^{2}\right) \gamma-k \beta^{2}}>0
\end{aligned}
$$

when $\left(a k-b^{2}\right) \gamma-k \beta^{2}>0, p_{8}{ }^{*}>p_{2}{ }^{*}>p_{4}{ }^{*}$; when $\left(a k-b^{2}\right) \gamma-k \beta^{2}<0$, $p_{8}{ }^{*}>p_{4}{ }^{*}>p_{2}{ }^{*}$.

$$
q_{4}{ }^{*}-q_{8}{ }^{*}=\frac{a k \gamma(a-\sigma) d}{\left(2 a k-b^{2}\right) \gamma-k \beta^{2}}>0, q_{8}{ }^{*}-q_{2}{ }^{*}=\frac{a \sigma k \gamma d}{\left(2 a k-b^{2}\right) \gamma-k \beta^{2}}>0,
$$

so $q_{4}{ }^{*}>q_{8}{ }^{*}>q_{2}{ }^{*}$.

$$
\begin{gathered}
R_{4}{ }^{*}-R_{8}{ }^{*}=\frac{k \gamma(a-\sigma) d\left[2\left(D_{0}-a C\right)+(a+\sigma) d\right]}{2\left[\left(2 a k-b^{2}\right) \gamma-k \beta^{2}\right]}>0, \\
R_{8}{ }^{*}-R_{2}{ }^{*}=\frac{k \gamma \sigma d\left[2\left(D_{0}-a C\right)+\sigma d\right]}{2\left[\left(2 a k-b^{2}\right) \gamma-k \beta^{2}\right]}>0
\end{gathered}
$$

then, $R_{4}{ }^{*}>R_{8}{ }^{*}>R_{2}{ }^{*}$.

Similarly, from the analysis in Table 6, it can be seen that, in centralized decisionmaking, compared with no government subsidies and government subsidies to consumers, the policy of subsidizing the farmer cooperative has the highest level of agricultural product preservation, sales efforts of the E-commerce platform and sales volume, and the overall supply chain profits are also the highest.

In summary, whether it is a decentralized decision or a centralized decision, for the supply chain composed of a farmer cooperative and an E-commerce platform, the effect of government subsidies is significantly better than that of no government subsidies, and the strategy of government subsidies to farmer cooperatives is better than other strategies. 


\subsection{Contract Coordination Mechanism of the Supply Chain under Government Subsidized the Farmer Cooperative}

From the above strategies of decentralized decision-making and centralized decisionmaking, no government subsidy, government subsidized the farmer cooperative, and government subsidized consumers, it is apparent that the strategy of government subsidized the farmer cooperative is the best, and the profit of the supply chain is maximized under centralized decision-making. Therefore, in order to make the best effect of government subsidies, first, directly subsidize farmer cooperative, and second, promote the cooperation between farmer cooperative and E-commerce platforms through contracts, so as to achieve the effect of centralized decision-making and achieve a win-win situation between farmer cooperative and E-commerce platforms.

Under the government's strategy of subsidizing the farmer cooperative, on the one hand, the farmer cooperative and the E-commerce platforms reach a consensus on the price of agricultural products, the fresh-keeping level of the farmer cooperative, and the sales effort of the E-commerce platform through contracts, so as to achieve the price, fresh-keeping level and sales efforts to maximize the overall profit of the supply chain. On the other hand, the two sides reached an agreement on the wholesale price of agricultural products to ensure that the profits realized by the two sides through the contract are not lower than their respective profits under separate decision-making. The core of coordination is the scope of the wholesale price of the farmer cooperative. The specific coordination mechanism is as follows.

Proposition 6. Under the contract coordination mechanism, the profit ranges of the E-commerce platform and the farmer cooperative are:

$$
\begin{gathered}
\frac{k \gamma\left[D_{0}-a(C-d)\right]^{2}}{2\left[2\left(2 a k-b^{2}\right) \gamma-k \beta^{2}\right]} \leq R_{l} \leq \frac{k \gamma\left[D_{0}-a(C-d)\right]^{2}\left\{3\left(2 a k-b^{2}\right) \gamma\left[\left(2 a k-b^{2}\right) \gamma-k \beta^{2}\right]+k^{2} \beta^{4}\right\}}{2\left[\left(2 a k-b^{2}\right) \gamma-k \beta^{2}\right]\left[2\left(2 a k-b^{2}\right) \gamma-k \beta^{2}\right]^{2}} \\
\frac{k \gamma^{2}\left(2 a k-b^{2}\right)\left[D_{0}-a(C-d)\right]^{2}}{2\left[2\left(2 a k-b^{2}\right) \gamma-k \beta^{2}\right]^{2}} \leq R_{f} \leq \frac{k \gamma^{2}\left(2 a k-b^{2}\right)\left[D_{0}-a(C-d)\right]^{2}}{2\left[\left(2 a k-b^{2}\right) \gamma-k \beta^{2}\right]\left[2\left(2 a k-b^{2}\right) \gamma-k \beta^{2}\right]}
\end{gathered}
$$

Proof. The purpose of contract coordination between the E-commerce platform and the farmer cooperative is to make the sum of the profits of the two parties after the coordination achieve the effect of centralized decision-making, and the profits of each party are not lower than the profits of the two parties in the decentralized decision-making. So

$$
\begin{aligned}
& R_{f}+R_{l}=\frac{k \gamma\left[D_{0}-a(C-d)\right]^{2}}{2\left[\left(2 a k-b^{2}\right) \gamma-k \beta^{2}\right]} R_{l} \geq \frac{k \gamma\left[D_{0}-a(C-d)\right]^{2}}{2\left[2\left(2 a k-b^{2}\right) \gamma-k \beta^{2}\right]} R_{f} \geq \frac{k \gamma^{2}\left(2 a k-b^{2}\right)\left[D_{0}-a(C-d)\right]^{2}}{2\left[2\left(2 a k-b^{2}\right) \gamma-k \beta^{2}\right]^{2}}, \\
& \frac{k \gamma\left[D_{0}-a(C-d)\right]^{2}}{2\left[2\left(2 a k-b^{2}\right) \gamma-k \beta^{2}\right]} \leq R_{l} \leq \frac{k \gamma\left[D_{0}-a(C-d)\right]^{2}\left\{3\left(2 a k-b^{2}\right) \gamma\left[\left(2 a k-b^{2}\right) \gamma-k \beta^{2}\right]+k^{2} \beta^{4}\right\}}{2\left[\left(2 a k-b^{2}\right) \gamma-k \beta^{2}\right]\left[2\left(2 a k-b^{2}\right) \gamma-k \beta^{2}\right]^{2}} \\
& \frac{k \gamma^{2}\left(2 a k-b^{2}\right)\left[D_{0}-a(C-d)\right]^{2}}{2\left[2\left(2 a k-b^{2}\right) \gamma-k \beta^{2}\right]^{2}} \leq R_{f} \leq \frac{k \gamma^{2}\left(2 a k-b^{2}\right)\left[D_{0}-a(C-d)\right]^{2}}{2\left[\left(2 a k-b^{2}\right) \gamma-k \beta^{2}\right]\left[2\left(2 a k-b^{2}\right) \gamma-k \beta^{2}\right]}
\end{aligned}
$$

Proposition 7. Under the government's strategy of subsidizing the farmer cooperative, in order to achieve the effect of centralized decision-making by the farmer cooperative and the E-commerce platform, in addition to external coordination of agricultural product prices, the fresh-keeping level of the farmer cooperative and sales efforts of the E-commerce platform, the wholesale of agricultural products needs to be internally coordinated through contracts. The price range is: 


$$
\begin{gathered}
\gamma D_{0}\left[\left(2 a k-b^{2}\right)^{2}\left(2 a k+3 b^{2}\right) \gamma^{2}-2\left(2 a k-b^{2}\right)\left(2 a k+b^{2}\right) k \gamma \beta^{2}+2 a k^{3} \beta^{4}\right]+a(C-d) \\
\frac{\left[\left(2 a k-b^{2}\right)^{2}\left(14 a k-11 b^{2}\right) \gamma^{3}-2\left(2 a k-b^{2}\right)\left(14 a k-9 b^{2}\right) k \gamma^{2} \beta^{2}+2\left(9 a k-5 b^{2}\right) \gamma k^{2} \beta^{4}-2 k^{3} \beta^{6}\right]}{2 a\left[\left(2 a k-b^{2}\right) \gamma-k \beta^{2}\right]\left[2\left(2 a k-b^{2}\right) \gamma-k \beta^{2}\right]^{2}} \\
\gamma D_{0}\left[\left(2 a k-b^{2}\right)\left(2 a k+b^{2}\right) \gamma-2 a k^{2} \beta^{2}\right] D_{0}+a(C-d) \\
\leq W \leq \frac{\left[\left(2 a k-b^{2}\right)\left(6 a k-5 b^{2}\right) \gamma^{2}-2\left(5 a k-3 b^{2}\right) k \gamma \beta^{2}+2 k^{2} \beta^{4}\right]}{2\left[\left(2 a k-b^{2}\right) \gamma-k \beta^{2}\right]\left[2\left(2 a k-b^{2}\right) \gamma-k \beta^{2}\right]}
\end{gathered}
$$

Proof. Assuming that the farmer cooperative and the E-commerce platform achieve winwin cooperation through contracts, under the government's strategy of subsidizing the farmer cooperative, the selling prices of agricultural products, the freshness preservation level of the farmer cooperative, and the sales efforts of the E-commerce platforms are respectively

$$
\begin{gathered}
p=\frac{k \gamma D_{0}+\left[\left(a k-b^{2}\right) \gamma-k \beta^{2}\right](C-d)}{\left(2 a k-b^{2}\right) \gamma-k \beta^{2}} \\
s=\frac{b \gamma\left[D_{0}-a(C-d)\right]}{\left(2 a k-b^{2}\right) \gamma-k \beta^{2}} \\
e=\frac{k \beta\left[D_{0}-a(C-d)\right]}{\left(2 a k-b^{2}\right) \gamma-k \beta^{2}}
\end{gathered}
$$

then $q=\frac{a k \gamma\left[D_{0}-a(C-d)\right]}{\left(2 a k-b^{2}\right) \gamma-k \beta^{2}}$.

Because $R_{f}=(W-C) q-\frac{1}{2} k s^{2}=(W-C) \frac{a k \gamma\left[D_{0}-a(C-d)\right]}{\left(2 a k-b^{2}\right) \gamma-k \beta^{2}}-\frac{k b^{2} \gamma^{2}\left[D_{0}-a(C-d)\right]}{2\left[\left(2 a k-b^{2}\right) \gamma-k \beta^{2}\right]^{2}}$

$$
\text { and } \frac{k \gamma^{2}\left(2 a k-b^{2}\right)\left[D_{0}-a(C-d)\right]^{2}}{2\left[2\left(2 a k-b^{2}\right) \gamma-k \beta^{2}\right]^{2}} \leq R_{f} \leq \frac{k \gamma^{2}\left(2 a k-b^{2}\right)\left[D_{0}-a(C-d)\right]^{2}}{2\left[\left(2 a k-b^{2}\right) \gamma-k \beta^{2}\right]\left[2\left(2 a k-b^{2}\right) \gamma-k \beta^{2}\right]} \text {, then }
$$

$$
\begin{gathered}
\gamma D_{0}\left[\left(2 a k-b^{2}\right)^{2}\left(2 a k+3 b^{2}\right) \gamma^{2}-2\left(2 a k-b^{2}\right)\left(2 a k+b^{2}\right) k \gamma \beta^{2}+2 a k^{3} \beta^{4}\right]+a(C-d) \\
\frac{\left[\left(2 a k-b^{2}\right)^{2}\left(14 a k-11 b^{2}\right) \gamma^{3}-2\left(2 a k-b^{2}\right)\left(14 a k-9 b^{2}\right) k \gamma^{2} \beta^{2}+2\left(9 a k-5 b^{2}\right) \gamma k^{2} \beta^{4}-2 k^{3} \beta^{6}\right]}{2 a\left[\left(2 a k-b^{2}\right) \gamma-k \beta^{2}\right]\left[2\left(2 a k-b^{2}\right) \gamma-k \beta^{2}\right]^{2}} \\
\gamma D_{0}\left[\left(2 a k-b^{2}\right)\left(2 a k+b^{2}\right) \gamma-2 a k^{2} \beta^{2}\right] D_{0}+a(C-d) \\
\leq W \leq \frac{\left[\left(2 a k-b^{2}\right)\left(6 a k-5 b^{2}\right) \gamma^{2}-2\left(5 a k-3 b^{2}\right) k \gamma \beta^{2}+2 k^{2} \beta^{4}\right]}{2\left[\left(2 a k-b^{2}\right) \gamma-k \beta^{2}\right]\left[2\left(2 a k-b^{2}\right) \gamma-k \beta^{2}\right]}
\end{gathered}
$$

Under the government's strategy of subsidizing the farmer cooperative, in order to achieve the effect of centralized decision-making, the E-commerce platform needs to reach an agreement on the wholesale price of agricultural products with the farmer cooperative, so as to increase the preservation level and expand sales on the basis of not reducing the profits of both parties, so as to achieve a win-win situation for the farmer cooperative, the E-commerce platform, and consumers.

\section{Numerical Analysis}

In order to verify the effects of different government subsidies, this paper gives specific examples for analysis. Assuming that the E-commerce platform only sells one kind of agricultural product, the demand function of agricultural products is $D=200-8 p+$ $6 s+5 e$, while $k=8$ and the cost function of preservation of the farmer cooperative is 
$g(s)=4 s^{2} \cdot \gamma=6$ and the sales promotion cost function of the E-commerce platform is $c(e)=3 e^{2}$. Let $C=10 \$, \sigma=4, d=1 \$$. Due to the balance of supply and demand, there will be $q=D=200-8 p+6 s+5 e$. When the government subsidizes consumers, sales is $q=D=200-8 p+6 s+5 e+4 d$

\subsection{Comparison of Two Decision-Making Models without Government Subsidies}

Substituting the known values into the various formulas in Table 2 to obtain the respective optimal decision, profit and overall profit value of the system for decentralized decision-making and centralized decision-making is as shown in Table 7.

From the analysis of the calculation example in Table 7, it can be seen that when the E-commerce platform and the farmer cooperative make decentralized decisions, the sales volume, the freshness preservation of agricultural products, the sales efforts of the Ecommerce platform, and the overall profit of the system are all low. When the E-commerce platform and the farmer cooperative realize centralized decision-making, the price of agricultural products will only increase by $2.01 \%$, but the freshness level of agricultural products will increase by $155.69 \%$, the sales volume will increase by $156.84 \%$, the sales efforts of the E-commerce platform will increase by $156.87 \%$, and the overall profit of the supply chain will increase by $59.45 \%$.

\subsection{Comparison of the Effects of Three Government Subsidy Strategies}

Substituting the known values into Tables 5 and 6, the optimal decision, profit, and the overall profit value of the system for different government subsidy strategies in decentralized decision-making and centralized decision-making are obtained, as shown in Table 8.

Table 7. The optimal decisions and profits of two decision models without government subsidies.

\begin{tabular}{ccccc}
\hline Parameter & $\begin{array}{c}\text { Decentralized } \\
\text { Decision-Making }\end{array}$ & $\begin{array}{c}\text { Centralized } \\
\text { Decision-Making }\end{array}$ & $\begin{array}{c}\text { Change } \\
\text { Amount }\end{array}$ & Rate of Change \\
\hline$s$ & 4.78 & 12.27 & 7.49 & $155.69 \%$ \\
\hline$e$ & 5.31 & 13.64 & 8.33 & $156.87 \%$ \\
\hline$p$ & 25.53 & 26.36 & 0.83 & $3.25 \%$ \\
\hline$q$ & 50.97 & 130.91 & 79.94 & $156.84 \%$ \\
\hline$W$ & 16.37 & - & - & - \\
\hline$R_{l}$ & 382.30 & - & - & - \\
\hline$R_{f}$ & 233.44 & - & - & - \\
\hline$R$ & 615.74 & 981.82 & 366.08 & $59.45 \%$ \\
\hline
\end{tabular}

From the analysis of calculation examples in Table 8, it can be seen that whether it is a decentralized decision or centralized decision, compared with non-government subsidies and government subsidies to consumers, under the strategy of government subsidies to the farmer cooperative, the freshness level, sales volume, the sales efforts of the E-commerce platform and the overall profit of the supply chain are all the highest. Although the sales price of agricultural products increases slightly, it brings about a significant increase in the freshness level, sales volume, sales efforts of the E-commerce platform, and the overall profit of the supply chain.

In summary, the government's strategy of subsidizing the farmer cooperative is better than government subsidies to consumers and no government subsidies, and centralized decision-making is better than decentralized decision-making. 
Table 8. Optimal decision and profit of different government subsidy strategies.

\begin{tabular}{|c|c|c|c|c|c|c|}
\hline \multirow{2}{*}{ Parameter } & \multicolumn{3}{|c|}{ Decentralized Decision-Making } & \multicolumn{3}{|c|}{ Centralized Decision-Making } \\
\hline & $\begin{array}{c}\text { No } \\
\text { Government } \\
\text { Subsidy }\end{array}$ & $\begin{array}{c}\text { Government } \\
\text { Subsidies to the } \\
\text { Farmer Cooperative }\end{array}$ & $\begin{array}{l}\text { Government } \\
\text { Subsidies to } \\
\text { Customers }\end{array}$ & $\begin{array}{c}\text { No } \\
\text { Government } \\
\text { Subsidy }\end{array}$ & $\begin{array}{c}\text { Government } \\
\text { Subsidies to the } \\
\text { Farmer Cooperative }\end{array}$ & $\begin{array}{c}\text { Government } \\
\text { Subsidies to } \\
\text { Customers }\end{array}$ \\
\hline s & 4.78 & 5.10 & 4.94 & 12.27 & 13.09 & 12.68 \\
\hline$e$ & 5.31 & 5.66 & 5.49 & 13.64 & 14.55 & 14.09 \\
\hline$p$ & 25.53 & 25.57 & 26.05 & 26.36 & 26.45 & 26.91 \\
\hline$q$ & 50.97 & 54.37 & 52.67 & 130.91 & 139.09 & 135.27 \\
\hline$W$ & 16.37 & 15.80 & 16.58 & - & - & - \\
\hline$R_{l}$ & 382.30 & 434.97 & 408.21 & - & - & - \\
\hline$R_{f}$ & 233.44 & 265.60 & 249.26 & - & - & - \\
\hline$R$ & 615.74 & 700.57 & 657.47 & 981.82 & 1116.22 & 1048.36 \\
\hline
\end{tabular}

7.3. Contract Coordination under the Government Subsidy Strategy

7.3.1. Coordination Strategy for Agricultural Product Wholesale Prices

Substituting known values into Formulas (20) and (21), the profit range of the farmer cooperative is [265.68, 681.13], and the profit range of the E-commerce platform is [435.09, 850.54]. Substituting the known value into formula (22), the coordination range of the wholesale price of the farmer cooperative is: $15.81 \leq W \leq 18.79$. When $W=17 \$$, the results of the coordination effect between the E-commerce platform and the farmer cooperative are shown in Table 9.

Table 9. Contract coordination results of the E-commerce platform and farmer cooperative.

\begin{tabular}{ccccc}
\hline Parameter & $\begin{array}{c}\text { Decentralized } \\
\text { Decision-Making }\end{array}$ & $\begin{array}{c}\text { Centralized } \\
\text { Decision-Making }\end{array}$ & $\begin{array}{c}\text { Profit } \\
\text { Coordination }\end{array}$ & Rate of Change \\
\hline$s$ & 5.10 & 13.09 & 13.09 & $241.69 \%$ \\
\hline$e$ & 5.66 & 14.55 & 14.55 & $157.07 \%$ \\
\hline$p$ & 25.57 & 26.45 & 26.45 & $3.44 \%$ \\
\hline$q$ & 54.37 & 139.64 & 139.64 & $156.83 \%$ \\
\hline$R_{l}$ & 15.80 & - & 17 & $7.59 \%$ \\
\hline$R_{f}$ & 435.09 & - & 684.49 & $57.32 \%$ \\
\hline$R$ & 265.68 & - & 431.73 & $62.5 \%$ \\
\hline
\end{tabular}

It can be seen from Table 9 that when the E-commerce platform and the farmer cooperative reach an agreement on the wholesale price of agricultural products, such as $17 \$$, the freshness of the farmer cooperative, the sales efforts of the E-commerce platform and the sales volume of agricultural products increased by $241.69 \%, 157.07 \%$ and $156.83 \%$ respectively. The profits of the farmer cooperative and the E-commerce platform increase by $62.5 \%$ and $57.32 \%$, respectively. At the same time, the coordination of wholesale price increases the profit of the system by $59.33 \%$.

\subsubsection{Sensitivity Analysis of Wholesale Price Coordination of Agricultural Products}

Within the coordination scope of wholesale prices of agricultural products, when the wholesale prices of agricultural products are different, the profit change trend of the E-commerce platform and farmers' cooperatives is as shown in Figure 1. 


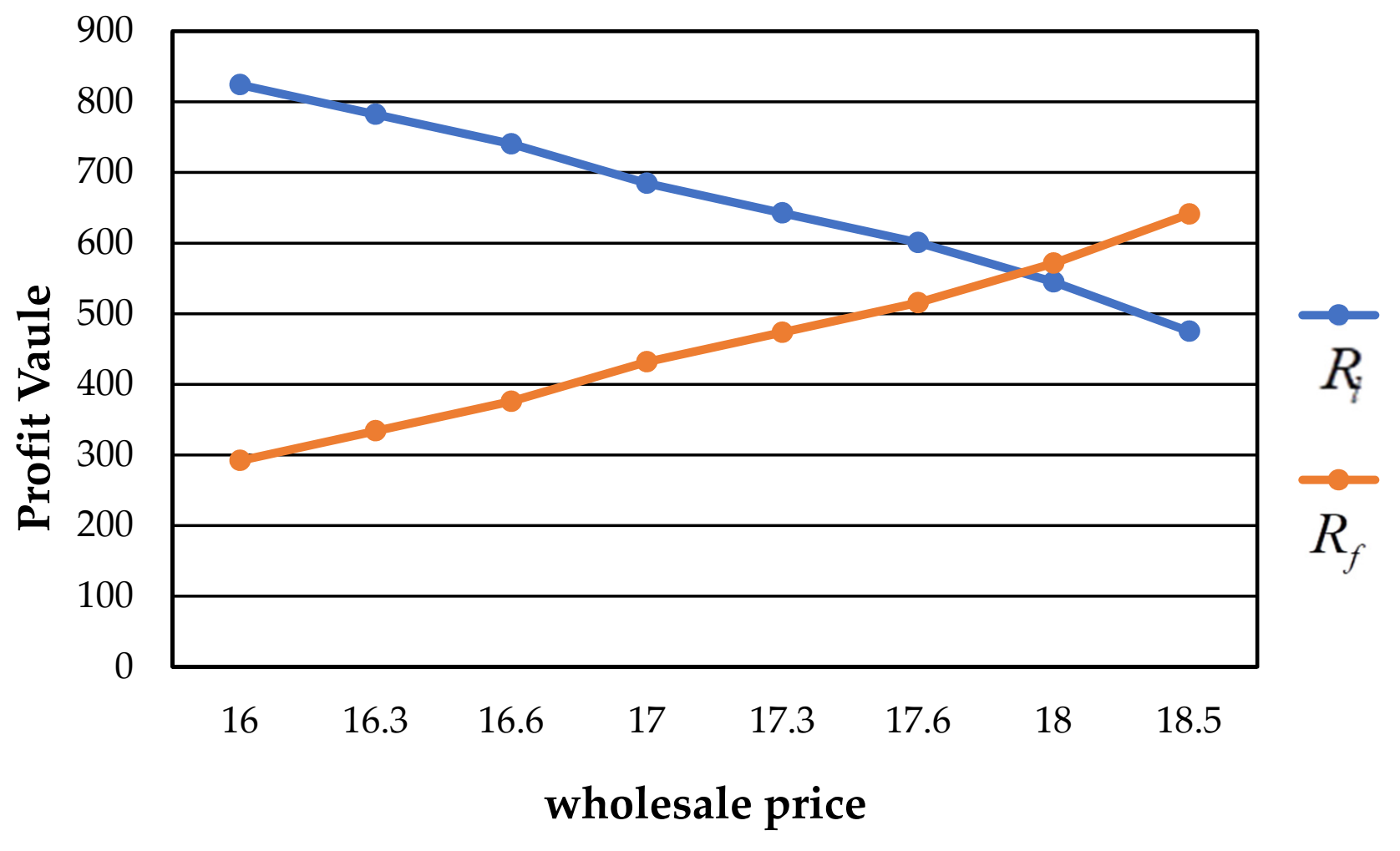

Figure 1. Sensitivity analysis of wholesale price coordination of agricultural products.

It can be seen from Figure 1 that with the increase in the wholesale price of agricultural products, the profits of farmer cooperatives will increase substantially. The specific coordination result of the wholesale price of agricultural products depends on the game between the two parties.

\section{Discussion, Conclusions, and Recommendations}

\subsection{Research Conclusions}

Without considering the subsidization, the results of the comparative analysis indicate that the sales volume, preservation level, sales efforts, and overall profit of the agricultural products E-commerce supply chain are significantly higher for centralized decisions (from the online shopping platform and agricultural cooperative) than for decentralized decisions.

In considering the subsidization, the results indicate that, for both centralized decisions and decentralized decisions, the benefits from subsidizing to the agricultural cooperative is similar from the subsidizing to the online shopping platform. However, the subsidizing to the agricultural cooperative/online shopping platform is better than the subsidizing to consumers and no subsidization. Under all circumstances, centralized decision-making is better than decentralized decision-making.

Therefore, it can be concluded that under the government's subsidies for agricultural cooperatives or online shopping platforms, both E-commerce platforms and farmer cooperatives can obtain the greatest benefits by taking the centralized decision on the online selling price of agricultural products.

\subsection{Theoretical Contributions}

This study provides research contributions from two aspects. First, for agriculture research, this study develops a profit model to evaluate different government subsidy 
strategies for the development of agricultural products E-commerce. Secondly, for the research on government subsidies, this research considers the structure of the electronic supply chain and examines the government subsidy strategies from the perspective of maximizing the benefits of the electronic supply chain. The details of the contribution are discussed below.

Previous research on fresh agricultural products E-commerce focused on supply chain models $[7,49,50]$, information technology and sharing [12,51], sales channels and coordination $[6,13,52]$. This research focuses on the agricultural product online shopping supply chain composed of the farmer cooperative, E-commerce platform, and consumers. This study explores the impacts of different strategies of government' subsidising among these three supply chain members in terms of freshness and sales efforts. This study contributes to agricultural research by developing a profit model to examine the effects of different government subsidy strategies on each member of the agricultural online shopping supply chain. This profit model covers the investment needed to improve the quality (such as freshness) of agricultural products selling online. It also includes the investment needed to increase sales (for example, sales efforts). Specifically, this profit model helps the government to know how to support the development of E-commerce of agricultural products by adopting various subsidy strategies. Researchers can further apply this profit model to evaluate different factors that support the development of the agricultural products E-commerce.

In the past, the research on government subsidies mainly focused on the manufacturing industry, aiming at low-carbon energy conservation and emission reduction [22,23], recycling of waste products [24,25], old for new [26,27] and so on. This study focuses on the E-commerce link of agricultural products from the perspective of government subsidies. This study extends the research on government subsidies to the online shopping supply chain of agricultural products. It contributes to the research on government subsidies by showing a new direction for researchers to consider when undertaking research about government subsidy decision-making. In addition, this study considers different strategies with centralized decision-making and decentralized decision-making in a supply chain. Previous studies on government subsidies mainly focused on the benefits of a part of the supply chain such as farmers [9]. This study considers the benefits for the whole supply chain. It provides researchers with a reference when configuring their research on government subsidies regarding a supply chain structure.

\subsection{Practical Implications}

For agricultural cooperatives, the fresh-keeping level of agricultural products in circulation is one of the important factors that affect the selling prices and sales volume of agricultural products online. Therefore, on the one hand, agricultural cooperatives must increase investment in equipment to ensure the freshness of agricultural products from the source, thereby increasing agricultural product sales online. On the other hand, agricultural cooperatives should strengthen the training of preservation technology for agricultural products. Agricultural cooperatives can fully use the opportunity of technical training for rural science and technology special commissioners (arranged by the government) to effectively improve the fresh-keeping processing level. The use of preservation technology ensures the freshness and quality of agricultural products. Therefore, agricultural products E-commerce can promote cost reduction, efficiency increase in circulation links, and improve the sales volume of agricultural products.

For E-commerce platforms, since their sales efforts can increase sales, they should fully utilize the channel advantages to increase the sales of agricultural products. First of all, the E-commerce platforms can establish a special area (hall) for agricultural product sales to intensify the promotion of agricultural products. This hall can improve the efficiency of consumers' online purchase of agricultural products and enhance consumers' service experiences. Secondly, the E-commerce platforms should actively strengthen cooperation with farmer cooperatives. They should protect farmer cooperatives' interests and enhance 
farmer cooperatives' confidence in online sales by formulating the purchase agreement price of agricultural products. This cooperation can further increase the enthusiasm of farmer cooperatives in planting agricultural products, achieving mutual benefits and resulting win-win for both sides.

For the government, government subsidy can help the development of agricultural products E-commerce to increase the sales of agricultural products so as to increase the overall profits of the supply chain system. Therefore, the government can increase agricultural product sales subsidies, encourage farmer cooperatives to improve the freshness of agricultural products that enhance consumers' satisfaction with online shopping, so as to improve the online sales volume of agricultural products.

\subsection{Research Limitations and Future Research Directions}

This study has the following limitations: In practical application, the demand function is affected by many factors; this paper only considers the influence of price, freshness, and sales efforts. In the follow-up study, more influencing factors would be considered. Second, the profit model simply applies a simple linear relationship, while the investment of the E-commerce platforms shows a quadratic relationship. Researchers can extend to other models based on this study. This study only considers one agricultural product. However, some agricultural products have high substitutability from time to time, and their demands influence each other. Researchers can further design a more complicated demand function with a set of agricultural products. When studying the effects of different strategies of government subsidies, only the impact on decision-making variables and the profits of various subjects are considered. Researchers can further consider non-monetary returns such as social welfare. This study only considers the effect of government price subsidies. In fact, government subsidies may be in different forms. Researchers can consider different types of subsidies. In addition, considering the differences between regions with unequal economic development in China, researchers can evaluate the performance of different subsidy strategies in different regions of China.

Author Contributions: Y.Z., H.T. and I.K.W.L. conceptualized the study; Y.Z., F.G. and I.K.W.L. supervised the data analysis and methodology; Y.Z. and F.G. performed the data analysis and the results; writing, Y.Z., F.G., H.T. and I.K.W.L.; quality assurance and project management, H.T. All authors have read and agreed to the published version of the manuscript.

Funding: This research was funded by Characteristic Innovation Project of Humanities and Social Science Research of Guangdong University (Grant 2021WTSCX092), Humanities and Social Sciences foundation of Ministry of Education in China (Grant 17YJC630230), and Macau University of Science and Technology Foundation (Grant FRG-19-033-MSB).

Institutional Review Board Statement: Not applicable.

Informed Consent Statement: Not applicable.

Data Availability Statement: No new data were created or analyzed in this study.

Conflicts of Interest: The authors declare no conflict of interest.

\section{References}

1. Yan, B.; Fan, J.; Wu, J.W. Channel choice and coordination of fresh agriculture product supply chain. Rairo-Oper. Res. 2021, 55, 679-699. [CrossRef]

2. Huo, Y.; Mu, H. Research on the Development of E-commerce Model of Agricultural Products. MATEC Web Conf. 2017, 100, 02040. [CrossRef]

3. Ma, C.; Wang, D.Y.; Hu, Z.Q.; Li, Z. Considerations of constructing quality, health and safety management system for agricultural products sold via e-commerce. Int. J. Agric. Biol. Eng. 2018, 11, 31-39. [CrossRef]

4. Ministry of agriculture and rural areas, Chinese Academy of Agricultural Sciences. China Agricultural E-Commerce Development Report (2020); China Agricultural Science and Technology Press: Beijing, China, 2021.

5. Han, X.P.; Bai, S.Z.; Yu, H. Pre-Sale Strategy for Fresh Agricultural Products Under the Consideration of Logistics Services. IEEE Access 2021, 9, 127742-127752. [CrossRef] 
6. Liu, Y.F. Innovation of Marketing Pattern of Fresh Agricultural Products Based on Internet plus and big Data Platform. Agro Food Ind. Hi-Tech 2017, 28, 1739-1743.

7. Juan, W.; Tao, Y.D. Reverse integration and optimisation of agricultural products e-commerce omnichannel supply chain under Internet technology. Acta Agric. Scand. Sect. B-Soil Plant Sci. 2021, 71, 604-612. [CrossRef]

8. Kang, K.; Wang, M.Z.; Luan, X.F. Decision-making and coordination with government subsidies and fairness concerns in the poverty alleviation supply chain. Comput. Ind. Eng. 2021, 152, 107058. [CrossRef]

9. Lilavanichakul, A. Development of agricultural e-commerce in Thailand. FFTC J. Agric. Policy 2021, 1, 7-16.

10. Liu, X.; Walsh, J. Study on Development Strategies of Fresh Agricultural Products E-commerce in China. Int. Bus. Res. 2019, 12, 61-70. [CrossRef]

11. Mustafiz, S.; Nakayasu, A.; Itabashi, M. Marketing of Vegetable Seeds: Practice and Behavioral Inclinations of Vegetable Seed Sellers and Farmers in Selected Areas of Bangladesh. Agriculture 2021, 11, 364. [CrossRef]

12. Luo, M.; Zhou, G.H.; Wei, W. Study of the Game Model of E-Commerce Information Sharing in an Agricultural Product Supply Chain based on fuzzy big data and LSGDM. Technol. Forecast. Soc. Chang. 2021, 172, 121017. [CrossRef]

13. Song, Z.L.; He, S.W. Contract coordination of new fresh produce three-layer supply chain. Ind. Manag. Data Syst. 2019, 119, 148-169. [CrossRef]

14. Zhang, Y.J.; Rong, F.; Wang, Z. Research on cold chain logistic service pricing-based on tripartite Stackelberg game. Neural Comput. Appl. 2020, 32, 213-222. [CrossRef]

15. Han, J.L.; Lin, N.; Ruan, J.H.; Wang, X.P.; Wei, W.; Lu, H.M. A Model for Joint Planning of Production and Distribution of Fresh Produce in Agricultural Internet of Things. IEEE Internet Things J. 2021, 8, 9683-9696. [CrossRef]

16. Gu, H.Y.; Wang, C.W. Impacts of the COVID-19 pandemic on vegetable production and countermeasures from an agricultural insurance perspective. J. Integr. Agric. 2020, 19, 2866-2876. [CrossRef]

17. Chiang, W.Y.K.; Chhajed, D.; Hess, J.D. Direct-marketing, indirect profits: A strategic analysis of dual-channel supply-chain design. Manag. Sci. 2003, 49, 1-20. [CrossRef]

18. Hsiao, L.; Chen, Y.J. Strategic Motive for Introducing Internet Channels in a Supply Chain. Prod. Oper. Manag. 2014, 23, 36-47. [CrossRef]

19. Yan, B.; Chen, Y.R.; He, S.Y. Decision making and coordination of fresh agriculture product supply chain considering fairness concerns. Rairo-Oper. Res. 2020, 54, 1231-1248. [CrossRef]

20. Zhang, H.; Xu, H.; Pu, X. Comparisons of Pre-Sale Strategies for a Fresh Agri-Product Supply Chain with Service Effort. Agriculture 2020, 10, 324. [CrossRef]

21. Mueller, R.A.E. E-commerce and entrepreneurship in agricultural markets. Am. J. Agric. Econ. 2001, 83, 1243-1249. [CrossRef]

22. Wu, X.Y.; Fan, Z.P.; Cao, B.B. Cost-sharing strategy for carbon emission reduction and sales effort: A nash game with government subsidy. J. Ind. Manag. Optim. 2020, 16, 1999-2027. [CrossRef]

23. Huang, W.X.; Zhou, W.H.; Chen, J.G.; Chen, X.H. The government's optimal subsidy scheme under Manufacturers' competition of price and product energy efficiency. Omega-Int. J. Manag. Sci. 2019, 84, 70-101. [CrossRef]

24. Zhan, X.L.; Tian, Y.; Liu, C.J.; Hou, A.L.; Ma, J.H. Study of the Complexity Game of Supply Chain Green Innovation Introduction under EPR Policy and Government Subsidies. Complexity 2020, 2020, 5342606. [CrossRef]

25. Wang, Y.Y.; Fan, R.J.; Shen, L.; Miller, W. Recycling decisions of low-carbon e-commerce closed-loop supply chain under government subsidy mechanism and altruistic preference. J. Clean. Prod. 2020, 259, 120883. [CrossRef]

26. Zhao, J.H.; Sun, N. Government subsidies-based profits distribution pattern analysis in closed-loop supply chain using game theory. Neural Comput. Appl. 2020, 32, 1715-1724. [CrossRef]

27. Feng, D.Z.; Shen, C.; Pei, Z. Production decisions of a closed-loop supply chain considering remanufacturing and refurbishing under government subsidy. Sustain. Prod. Consum. 2021, 27, 2058-2074. [CrossRef]

28. Wang, W.L.; Zhang, S.X.; Zhang, L.L.; Liu, Q. Government Subsidy Policies and Corporate Social Responsibility. IEEE Access 2020, 8, 112814-112826. [CrossRef]

29. Xue, J.; Gong, R.F.; Zhao, L.J.; Ji, X.Q.; Xu, Y. A Green Supply-Chain Decision Model for Energy-Saving Products That Accounts for Government Subsidies. Sustainability 2019, 11, 2209. [CrossRef]

30. Ma, W.M.; Zhang, R.R.; Chai, S.W. What Drives Green Innovation? A Game Theoretic Analysis of Government Subsidy and Cooperation Contract. Sustainability 2019, 11, 5584. [CrossRef]

31. Meng, Q.F.; Li, M.W.; Li, Z.; Zhu, J. How Different Government Subsidy Objects Impact on Green Supply Chain Decision considering Consumer Group Complexity. Math. Probl. Eng. 2020, 2020, 5387867. [CrossRef]

32. Chen, Y.H.; Wen, X.W.; Wang, B.; Nie, P.Y. Agricultural pollution and regulation: How to subsidize agriculture? J. Clean. Prod. 2017, 164, 258-264. [CrossRef]

33. Garnett, T.; Appleby, M.C.; Balmford, A.; Bateman, I.J.; Benton, T.G.; Bloomer, P.; Burlingame, B.; Dawkins, M.; Dolan, L.; Fraser D.; et al. Sustainable Intensification in Agriculture: Premises and Policies. Science 2013, 341, 33-34. [CrossRef]

34. Schmedtmann, J.; Campagnolo, M.L. Reliable Crop Identification with Satellite Imagery in the Context of Common Agriculture Policy Subsidy Control. Remote Sens. 2015, 7, 9325-9346. [CrossRef]

35. Perez, L.P.Y.; Alcantara, J.R.M.; Lopez, A.M. Beyond income transfers to farmers, the macroeconomic spillover of CAP payments in Aragon (Spain), 2007-2013. New Medit 2014, 13, 30-38. 
36. Akkaya, D.; Bimpikis, K.; Lee, H. Government Interventions to Promote Agricultural Innovation. MESom-Manuf. Serv. Oper. Manag. 2021, 23, 437-452.

37. Yadav, P.; Davies, P.J.; Abdullah, S. Reforming capital subsidy scheme to finance energy transition for the below poverty line communities in rural India. Energy Sustain. Dev. 2018, 45, 11-27. [CrossRef]

38. Kang, K.; Zhao, Y.J.; Ma, Y.F.; Li, Z.M. Green supply chain poverty alleviation through microfinance game model and cooperative analysis. J. Clean. Prod. 2019, 226, 1022-1041. [CrossRef]

39. Yang, J.; Lin, Y.J.; Wu, F.Z.; Chen, L. Subsidy and Pricing Model of Electric Vehicle Sharing Based on Two-Stage Stackelberg Game-A Case Study in China. Appl. Sci. 2019, 9, 1631. [CrossRef]

40. Stackelberg, H. Marktform und Gleichgewicht; Springer: Vienna, Austria, 1934; (An English translation appeared in The Theory of the Market Economy, Oxford University Press: Oxford, UK, 1952).

41. Sexton, R.J. Imperfect competition in agricultural markets and the role of cooperatives: A spatial analysis. Am. J. Agric. Econ. 1990, 72, 709-720. [CrossRef]

42. Zhong, Y.G.; Guo, F.F.; Wang, Z.Q.; Tang, H.J. Coordination Analysis of Revenue Sharing in E-Commerce Logistics Service Supply Chain With Cooperative Distribution. Sage Open 2019, 9, 2158244019870536. [CrossRef]

43. Zhong, Y.G.; Guo, F.F.; Tang, H.J.; Chen, X.M. Research on Coordination Complexity of E-Commerce Logistics Service Supply Chain. Complexity 2020, 2020, 7031543. [CrossRef]

44. Ghosh, D.; Shah, J. A comparative analysis of greening policies across supply chain structures. Int. J. Prod. Econ. 2012, 135, 568-583. [CrossRef]

45. Zhao, J.; Wei, J. The coordinating contracts for a fuzzy supply chain with effort and price dependent demand. Appl. Math. Model. 2014, 38, 2476-2489. [CrossRef]

46. Ma, P.; Wang, H.Y.; Shang, J. Supply chain channel strategies with quality and marketing effort-dependent demand. Int. J. Prod. Econ. 2013, 144, 572-581. [CrossRef]

47. Liu, Z.G.; Anderson, T.D.; Cruz, J.M. Consumer environmental awareness and competition in two-stage supply chains. Eur. J. Oper. Res. 2012, 218, 602-613. [CrossRef]

48. Yu, J.J.; Tang, C.S.; Shen, Z.J.M. Improving Consumer Welfare and Manufacturer Profit via Government Subsidy Programs: Subsidizing Consumers or Manufacturers? MESom-Manuf. Serv. Oper. Manag. 2018, 20, 752-766.

49. Ren, J.J.; Li, H.X.; Zhang, M.M.; Wu, C. Massive-scale graph mining for e-commerce cold chain analysis and optimization. Future Gener. Comput. Syst.-Int. J. Escience 2021, 125, 526-531. [CrossRef]

50. Huang, X.R.; Xie, R.H.; Huang, L.J. Real-time emergency management mode of cold chain logistics for agricultural products under the background of "Internet plus". J. Intell. Fuzzy Syst. 2020, 38, 7461-7473. [CrossRef]

51. Zhu, Z.J.; Bai, Y.H.; Dai, W.H.; Liu, D.; Hu, Y. Quality of e-commerce agricultural products and the safety of the ecological environment of the origin based on 5G Internet of Things technology. Environ. Technol. Innov. 2021, 22, 101462. [CrossRef]

52. Hu, Q.F.; Xu, Q.Y.; Xu, B. Introducing of Online Channel and Management Strategy for Green Agri-food Supply Chain based on Pick-Your-Own Operations. Int. J. Environ. Res. Public Health 2019, 16, 1990. [CrossRef] 